\title{
Hybrid membrane-coated nanosuspensions for multi-modal anti-glioma therapy via drug and antigen delivery
}

Wenyan Hao, Yuexin Cui, Yueyue Fan, Mengyu Chen, Guobao Yang, Yuli Wang*, Meiyan Yang, Zhiping Li, Wei Gong, Yang Yang ${ }^{*}$ and Chunsheng Gao*

\begin{abstract}
Background: Glioma is one of the deadliest human cancers. Although many therapeutic strategies for glioma have been explored, these strategies are seldom used in the clinic. The challenges facing the treatment of glioma not only involve the development of chemotherapeutic drugs and immunotherapeutic agents, but also the lack of a powerful platform that could deliver these two moieties to the targeted sites. Herein, we developed chemoimmunotherapy delivery vehicles based on C6 cell membranes and DC membranes to create hybrid membrane-coated DTX nanosuspensions (DNS-[C6\&DC]m).

Results: Results demonstrated successful hybrid membrane fusion and nanosuspension functionalization, and DNS[C6\&DC]m could be used for different modes of anti-glioma therapy. For drug delivery, membrane coating could be applied to target the source cancer cells via a homotypic-targeting mechanism of the C 6 cell membrane. For cancer immunotherapy, biomimetic nanosuspension enabled an immune response based on the professional antigenpresenting characteristic of the dendritic cell membrane (DCm), which carry the full array of cancer cell membrane antigens and facilitate the uptake of membrane-bound tumor antigens for efficient presentation and downstream immune $\mathrm{n}$.
\end{abstract}

Conclusion: DNS-[C6\&DC]m is a multifunctional biomimetic nano-drug delivery system with the potential to treat gliomas through tumor-targeted drug delivery combined with immunotherapy, thereby presenting a promising approach that may be utilized for multiple modes of cancer therapy.

Keywords: Glioma, Blood-brain barrier, Biomimetic nanosuspensions, Chemotherapy, Immunotherapy

\footnotetext{
*Correspondence: wangyuli764@126.com; amms2013@126.com; gaocs@bmi.ac.cn

State Key Laboratory of Toxicology and Medical Countermeasures, Beijing Institute of Pharmacology and Toxicology, Beijing 100850, People's

Republic of China
}

(c) The Author(s) 2021. Open Access This article is licensed under a Creative Commons Attribution 4.0 International License, which permits use, sharing, adaptation, distribution and reproduction in any medium or format, as long as you give appropriate credit to the original author(s) and the source, provide a link to the Creative Commons licence, and indicate if changes were made. The images or other third party material in this article are included in the article's Creative Commons licence, unless indicated otherwise in a credit line to the material. If material is not included in the article's Creative Commons licence and your intended use is not permitted by statutory regulation or exceeds the permitted use, you will need to obtain permission directly from the copyright holder. To view a copy of this licence, visit http://creativecommons.org/licenses/by/4.0/. The Creative Commons Public Domain Dedication waiver (http://creativeco mmons.org/publicdomain/zero/1.0/) applies to the data made available in this article, unless otherwise stated in a credit line to the data. 


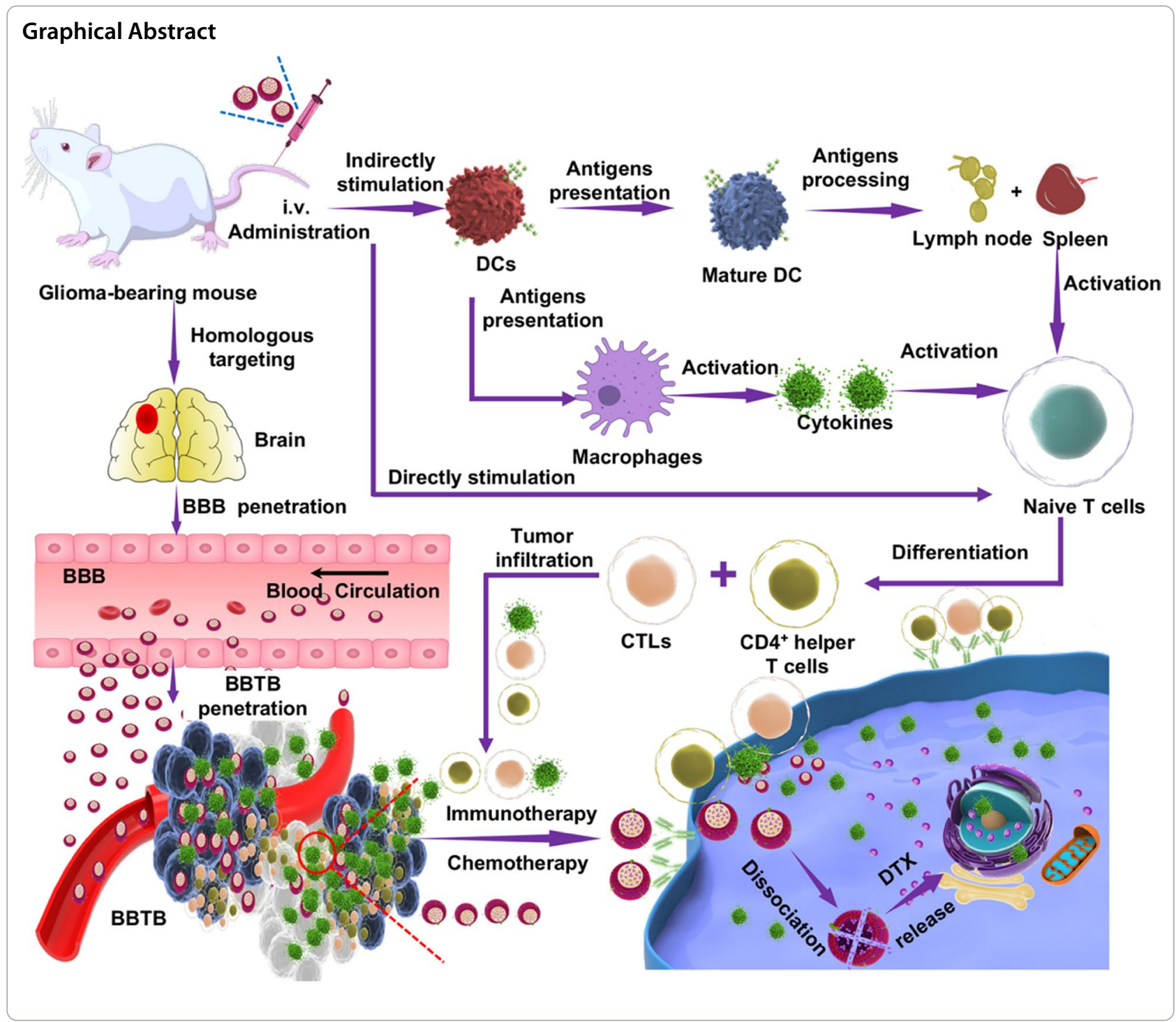

\section{Background}

Glioma is one of the deadliest human cancers, with a median survival time of less than 24 months and a 5 -year survival rate of only $2-4 \%[1,2]$. This short survival expectation has drawn significant interest from doctors and scientists developing combinatorial therapies, especially chemotherapy and immunotherapy combination treatment, to improve patient outcomes [3]. While other tumors have responded favorably to trials combining immunotherapy and chemotherapy, glioma remains uniformly deadly with minimal increases in overall survival. Gliomas differ from others because they are isolated behind the physiological barrier (the blood-brain barrier, $\mathrm{BBB}$ ) and the pathological barrier (blood-brain tumor barrier, BBTB), harbor increased heterogeneity and mutational burden, and cause immunosuppression from the brain environment and tumor itself [4, 5]. Given these limitations, chemotherapy and immune checkpoint blockade agents reach the glioma itself in very limited amounts. Therefore, the challenges facing the treatment of glioma not only involve the development of chemotherapeutic drugs and immunotherapeutic agents, but also the lack of a powerful platform that could deliver these two moieties to the targeted sites.

To date, many nanotechnology-based delivery systems (NDDSs) [6, 7] have been developed for the co-delivery of these two moieties; however, none of these systems have been approved by the US Food and Drug Administration for treating central nervous system (CNS) diseases [8]. Currently, almost all NDDSs essentially depend on the function of the materials they are made of, to target tumors; however, these materials only serve as excipients 
without any innate therapeutic efficacy. Tailor-made materials or the co-loading of multi-therapeutic agents often involve complex fabrication processes, which may cause variations in batch-to-batch reproducibility and reduce the stability of NDDSs, often resulting in unsatisfactory therapeutic outcomes [9]. Moreover, these systems suffer from the inherent limitations of synthetic materials, such as potential adverse side effects. Therefore, the design of a simple yet effective and safe NDDS is of great significance for clinical translation.

New frontiers in the field of NDDS are advancing research on biomimetic nanocarriers. Among these, cell membrane-coated nanoparticles (NPs) have been widely investigated for cancer therapy, ranging from enhanced efficacy in cancer drug delivery to enhanced immunogenicity of cancer vaccines [10-12]. For drug delivery, these types of biomimetic NPs exhibit unique functions from the source cells, providing an alternative strategy for overcoming biological obstacles and improving drug delivery efficiency $[13,14]$. However, for these biomimetic NPs, a large quantity of synthetic materials is required as a scaffold, often resulting in low drug loading yields. High drug loading can help increase the drug concentration at the target site, which helps to achieve an improved tumor inhibition effect. In this study, we extended cell membrane-coating technology to nanosuspensions. Similarly to a "pure drug particle," nanosuspensions have high drug carrying capacity due to the absence of a carrier, which helps to boost drug concentration at the targeted sites, and are readily translatable to the clinical arena $[2,15]$.

In addition to drug delivery, cell membrane-bound tumor antigens are also used to train the immune system to recognize and fight cancer, and mimic particulate carriers modified with these surface antigens have been previously prepared to improve vaccine efficacy [16-18]. As professional antigen-presenting cells, dendritic cells (DCs) can mobilize a variety of immune resistance mechanisms [19-21]. Mature DCs stimulated by tumor-associated antigens can promote the proliferation and activation of $\mathrm{CD}^{+}$and $\mathrm{CD} 4^{+} \mathrm{T}$ lymphocytes. Activated $C D 8^{+} \mathrm{T}$-lymphocytes (CTLs) specifically recognize tumor cells and induce tumor apoptosis [22, 23]. Moreover, activated $\mathrm{CD} 4^{+}$helper $\mathrm{T}$ lymphocytes upregulate the expression of major histocompatibility complex (MHC) molecules on the surface of tumor cells, thereby helping CTLs to recognize tumor cells and further induce cancer cell apoptosis [24]. Recently, DC-based immunotherapy has received widespread attention [25]. DC vaccines have been proven effective and safe in patients with glioblastoma, melanoma, renal cell carcinoma, and prostate and ovarian cancers [26]. Unfortunately, based on basic science and clinical trial data of the past 20 years, the efficacy of these vaccines is still far below expectations (only 10-15\%) [27]. Analyzing the reasons for this failure, two main factors were identified: (1) Most of the tumor DC vaccines target a single antigen; however, tumor cells can easily escape immune effects against a single epitope through antigen mutation. (2) Extracted tumor proteins are easily degraded by proteolytic enzymes in the body, which leads to unsustainable immune effects and difficulty in obtaining an ideal therapeutic effect, thus complicating the extraction process. Therefore, efficient antigen loading and improved stability are essential for DC vaccine optimization. Generally, cancer cells bear a broad category of antigens, including tumor-associated and tumor-specific antigens, and high levels of tumor antigens within cancer vaccines are required to reach the threshold for $\mathrm{T}$ cell recognition, thereby breaking immunological tolerance [28-30]. To maximize tumorspecific immune response, therefore, the cytomembrane vaccine, which was generated based on the fusion of the cytomembranes between cancer cells and DCs, is an exciting strategy that is readily translatable to the clinical arena [16, 31]. In addition, cancer cell membranes have domains that adhere to homologous cells and homologous binding proteins, which can provide nanomedicines coated with cancer cell membranes with tumor-targeting properties [32-34]. More recently, Xu et al. have reported a study of nanoparticles coated with functional DC membrane for combining photodynamic therapy and immunotherapy to terminate tumor growth. This suggested that the presence of tumor-associated antigens and T cell stimulating factors in DCm cloak [35]. Inspired by these natural properties, in this study, we fused membrane materials derived from glioma cells with DCm to create a hybrid biomimetic coating. Compared to cellular vaccines, the hybrid membrane possesses better biosafety, easier large-scale fabrication, and longer storage properties because of the exclusion of genetic materials. Because they are inherited from two parent cell lines, hybrid membranes are expected to confer not only a continuous source of tumor antigens, which can be presented by the $\mathrm{DCm}$ for $\mathrm{T}$ cell activation and offer strong immune responses against glioma cells, but also the driving force for drug delivery at glioma sites.

Here, we tested the ability of hybrid membranecoated nanosuspensions for multiple modes of antiglioma therapy (Fig. 1). To this end, we developed chemoimmunotherapy delivery vehicles based on C6 cell membranes and DC membranes to create hybrid membrane-coated nanosuspensions (DNS-[C6\&DC] m). Specifically, we chose docetaxel (DTX) [36], an insoluble chemotherapeutic drug with severe toxicity, as a model drug for the synthesis of DTX NS (DNS). 


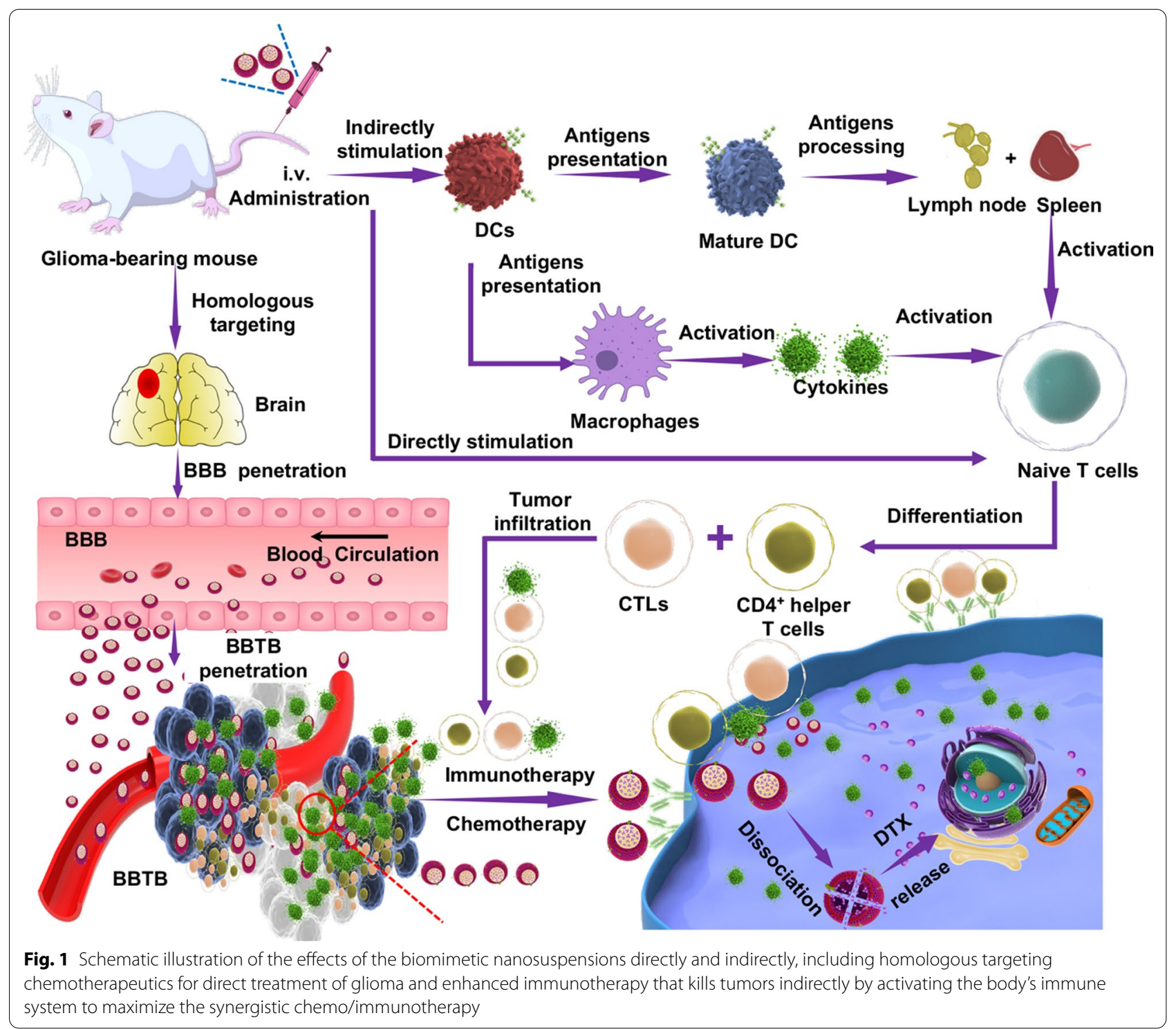

Although several studies related to biomimetic NPs, including hybrid membrane-coated NPs, have been previously conducted [37-39], most of them focused on monotherapy rather than combinatorial therapies. To our knowledge, this is the first study on the use of hybrid membrane-coated nanosuspensions for multiple modes of anti-glioma therapy via the delivery of high levels of tumor antigens and high doses of drug. The physical and chemical properties of DNS-[C6\&DC] $\mathrm{m}$ were characterized, and tumor targeting, immune activation ability, glioma inhibitory effect, and biological safety were assessed. Our findings provide valuable preclinical data to validate a noninvasive, efficient biomimetic nanoplatform for chemo-immunotherapy of glioma, an intractable and deadly malignant disease.

\section{Materials and methods \\ Materials}

Hypromellose E5 (HPMC E5) and sodium deoxycholate (SDC) were provided by Fenglijingqiu Commerce and Trade Co., Ltd. (Beijing, China). Lecithin was purchased from Yuanye Bio-Technology Co., Ltd. (Shanghai, China). Anti-ICAM, anti-CD44, anti-CD80, anti-MHC I, antiCD31, anti-CD8a, anti-CD86, and anti-CD4 antibodies were purchased from Abcam (Cambridge, UK). DTX was acquired from Aladdin Biochemical Technology Co., Ltd. (Shanghai, China). All chemical reagents were of 
analytical grade and were purchased from Macklin Biochemical Co., Ltd.

\section{Cells and experimental animals}

C6 glioma cells, RAW264.7 cells, bEnd.3 cells (mouse brain microvascular endothelial cells), and HUVECs (human umbilical vein endothelial cells) were supplied by the Cell Resource Center of IBMS (Beijing, China) and cultured in Dulbecco's modified Eagle's medium (DMEM) containing 10\% fetal bovine serum (FBS; Gibco) and $100 \mathrm{IU}$ penicillin.

Both female and male ICR mice (initially weighing 18-22 g) were purchased from SPF Biotechnology Co., Ltd. (permit number: SCXK 2019-0010, Beijing, China).

\section{Preparation and characterization of DNS}

DNS was prepared using an ultrasonic precipitation method [40]. DTX $(10 \mathrm{mg})$ was dissolved in $1 \mathrm{~mL}$ ethanol and mixed with $50 \mathrm{mg}$ lecithin as the oil phase. A mixed solution of $0.5 \mathrm{mg} / \mathrm{mL}$ HPMC E5 and $4 \mathrm{mg} / \mathrm{mL}$ surfactant SDC was used as the water phase. The water phase was then placed in an ice bath ultrasound (800 W). The oil phase was slowly dripped into the water phase, stirred while dripping, and ultrasonicated for $5 \mathrm{~min}$ after the dripping was concluded. The organic solvent was volatilized by magnetic stirring in an ice bath for $12 \mathrm{~h}$. The prepared DNS was stored at $4{ }^{\circ} \mathrm{C}$ until further use.

The nanoparticle size (diameter, $\mathrm{nm}$ ) and surface charge (zeta potential, $\mathrm{mV}$ ) of the prepared formulations were measured using dynamic light scattering (DLS) (Litesizer 500, Anton Parr, Austria). The prepared DNS was stored in $1 \times$ phosphate-buffered saline (PBS) or PBS containing $10 \% \mathrm{FBS}$ at $37^{\circ} \mathrm{C}$ to observe its stability, which was analyzed by measuring the particle size and zeta potential within $72 \mathrm{~h}$. The morphology of the DNS was characterized using transmission electron microscopy (TEM; H-7650, Hitachi, Japan). Drug powder was prepared using a freeze-drying method. Briefly, $20 \mathrm{~mL}$ of DNS was placed in a $50 \mathrm{~mL}$ beaker and pre-frozen at $-80{ }^{\circ} \mathrm{C}$ for $4 \mathrm{~h}$, after which it was freeze-dried for $24 \mathrm{~h}$ to obtain a solid DNS. DTX, HPMC E5, SDC, lecithin, physical mixture, and solid DNS were acquired for X-ray diffraction (XRD, D8 advance, Bruker, Germany) analysis at $2{ }^{\circ} \mathrm{C} / \mathrm{min}$. Scanning angles between $5^{\circ}$ and $90^{\circ}$ were used to observe the crystal changes of the drug. Further, differential scanning calorimetry was utilized to validate the physical state and crystal shape of the drug, at $10{ }^{\circ} \mathrm{C}$ $/ \mathrm{min}$, within the temperature range $40-300{ }^{\circ} \mathrm{C}$. Fourier transform infrared absorption spectrometry (FTIR) was used for drug analysis and identification (wave number was $4000-450 \mathrm{~cm}^{-1}$ ) to determine whether the drug molecules were changed.

\section{Generation of DCs}

DCs were isolated from ICR mice. Briefly, bone marrow mesenchymal stem cells were extracted from the bone marrow cavity of mouse femur and tibia bones, and cultured in RPMI-1640 medium containing 20\% FBS. The medium contained recombinant IL-4 $(10 \mathrm{ng} / \mathrm{mL})$ and GM-CSF $(10 \mathrm{ng} / \mathrm{mL})$. After 7 days, DCs were collected for further use.

\section{Isolation of DC membrane and C6 cancer cell membrane}

According to a previously reported method [41], C6 glioma cells were cultured in DMEM medium containing $10 \% \mathrm{FBS}\left(37^{\circ} \mathrm{C}, 5 \% \mathrm{CO}_{2}\right)$. When cell density reached $80-90 \%$, cells were digested with trypsin, centrifuged at $2000 \mathrm{rpm} / \mathrm{min}$ to collect cells, and then washed with PBS solution. Tumor cells were dispersed in 25\% PBS hypo-osmotic solution containing protease inhibitors, centrifuged at 20,000 rpm to remove cancer cell nuclei and other substances, and then centrifuged again to obtain cancer cell membranes $(10,000 \mathrm{rpm})$. DCs were collected and washed three times with cooled PBS $(\mathrm{pH}$ 7.4). Cell pellets were then suspended in a hypotonic lysis buffer containing phenylmethanesulfonyl fluoride and incubated in an ice bath for $15 \mathrm{~min}$ according to the manufacturer's instructions. Subsequently, cells were broken using a repeated freeze-thaw method three times and further centrifuged at $700 \times g$ for $10 \mathrm{~min}$ at $4{ }^{\circ} \mathrm{C}$. The resultant supernatant was further centrifuged at $20,000 \times g$ for 30 min to collect cracked cell membranes. These cell membrane products were then lyophilized and stored at $-80{ }^{\circ} \mathrm{C}$. The frozen membrane materials were rehydrated in ultrapure water prior to future use. The protein content in the membranes were determined using the bicinchoninic acid (BCA) protein assay to prepare DNS-[C6\&DC]m.

\section{Membrane fusion study}

To prepare a biomimetic nanosuspension with a hybrid cell membrane as a carrier, first we verified whether it is possible to combine $\mathrm{C6m}$ and $\mathrm{DCm}$. To conduct the Förster resonance energy transfer (FRET) study, two lipophilic dyes were employed: $1,1^{\prime}$-dioctadecyl-3,3,3', $3^{\prime}$ tetramethylindodicarbocyanine, 4-chlorobenzenesulfonate salt (DiD, excitation/emission $=644 / 663 \mathrm{~nm}$ ) and 1,1'-dioctadecyl-3,3,3',3'-tetramethylindocarbocyanine perchlorate (DiI, excitation/emission $=549 / 565 \mathrm{~nm}$ ). The ultrasound fusion method was utilized for fusing the $\mathrm{C} 6$ and DC membranes. C6 cell membrane was stained with $\mathrm{DiD}$ and DiI, and with respect to $\mathrm{C} 6$ membrane protein, the final ratios were 0.2 and $1.26 \mathrm{wt} \%$ for DiI and DiD, respectively. A solution containing the $\mathrm{C} 6$ membrane was then added to the vial and stirred at $37{ }^{\circ} \mathrm{C}$ for $1 \mathrm{~h}$. 
Afterward, free dye was washed away by centrifuging the membrane at $10,000 \times g$ for $15 \mathrm{~min}$, three times. DC membrane was added to the DiI/DiD-doped C6 membrane at DC membrane to $\mathrm{C} 6$ membrane protein weight ratios of 5:1, 3:1, 1:1, and 0:1, followed by sonication ( $300 \mathrm{~W}, 5 \mathrm{~min}$ ) to complete membrane fusion. The fluorescence spectrum of each sample was read using a plate reader (Tecan Spark, Austria) with an excitation wavelength of 500-650 $\mathrm{nm}$ under different mixing ratios $(\mathrm{DCm} / \mathrm{C} 6 \mathrm{~m})$. The fluorescence recovery of the donor (C6-DiI) at a low emission peak (nm) was utilized to indicate the increased amount of fusion.

\section{Preparation and Characterization of DNS-[C6\&DC]m}

DNS solution $(1 \mathrm{~mL}, 1 \mathrm{mg} / \mathrm{mL})$ was added to [C6\&DC]m solution $(0.5 \mathrm{~mL}, 0.3 \mathrm{mg} / \mathrm{mL})$ and sonicated $(300 \mathrm{~W})$ for $10 \mathrm{~min}$ in an ice bath to achieve the [C6\&DC]m coating. The mixture solution was centrifuged at $10,000 \mathrm{rpm}$ for $5 \mathrm{~min}$ to remove the excess membrane, and the resulting DNS-[C6\&DC] $\mathrm{m}$ was resuspended in deionized water for future use. DNS-[C6\&DC]m was acquired by ultrasonic treatment for $5 \mathrm{~min}$. The morphology was characterized using TEM, and the size and zeta potential of DNS$[C 6 \& D C] \mathrm{m}$ were measured using DLS. DNS-[C6\&DC]m was stored in either $1 \times$ PBS or PBS containing $10 \%$ FBS at $37{ }^{\circ} \mathrm{C}$. Stability analysis was carried out by measuring the particle size and zeta potential within $72 \mathrm{~h}$. The drug loading efficiency (LE) and encapsulation efficiency (EE) of DNS-[C6\&DC]m were determined by HPLC (Agilent1200, USA) [42, 43]. Briefly, $5 \mathrm{mg}$ (W) of the lyophilized DNS-[C6\&DC]m powder was taken into a measuring flask, dissolved in acetonitrile and constant volume to $100 \mathrm{~mL}$, centrifuged at $12,000 \mathrm{r} \cdot \mathrm{min}-1$ for $20 \mathrm{~min}, 200$ $\mu \mathrm{L}$ of supernatant was taken, and the concentration of non-loaded DTX in supernatant was measured by HPLC at $272 \mathrm{~nm}$ and calculated based on a pre-established DTX standard curve. LE and EE of DNS-[C6\&DC]m can be determined as follows: $\mathrm{LE}=\mathrm{M}_{\mathrm{DTX} \text {-loaded }} /\left(\mathrm{M}_{\text {[C6\&DC] }}\right.$ $\left.\mathrm{m}+\mathrm{M}_{\text {DTX-loaded }}\right), E E=\mathrm{M}_{\text {DTX-loaded }} / \mathrm{M}_{\text {DTX-initial }} \cdot \mathrm{M}_{\text {DTX-initial }}$ is the initial mass of DTX used for DNS-[C6\&DC]m preparation. $\mathrm{M}_{[\mathrm{C} 6 \& D C] \mathrm{m}}$ is the mass of [C6\&DC]m used for DNS-[C6\&DC]m preparation. $\mathrm{M}_{\mathrm{DTX} \text {-loaded }}$ is the mass of DTX loaded in [C6\&DC] $\mathrm{m}$, which was determined by subtracting the amount of DTX in the supernatant from $\mathrm{M}_{\text {DTX-initial }}$.

\section{Protein determination}

SDS-polyacrylamide gel electrophoresis (SDS-PAGE) was employed to examine the protein profile of DNS, DNS-C6m, DNS-DCm, and DNS-[C6\&DC]m [32]. In brief, proteins were extracted with RIPA lysis buffer, and the total protein amount was quantified using a BCA protein assay kit. The extracted proteins were then mixed with SDS loading buffer and heated at $100{ }^{\circ} \mathrm{C}$ for $10 \mathrm{~min}$. SDS-PAGE buffer was used as the run buffer. An equal amount of protein was added to the well containing $10 \%$ SDS-PAGE gel, according to the manufacturer's instructions. For the assembly image, the protein was stained with Coomassie blue and imaged $12 \mathrm{~h}$ after water decolorization. Proteins were transferred to polyvinylidene fluoride membranes for western blot analysis. Different samples were treated with anti-CD44, anti-ICAM, antiMHC I, and anti- CD80, and then anti-mouse IgG secondary antibody conjugated with horseradish peroxidase was further incubated at $37^{\circ} \mathrm{C}$ for $1 \mathrm{~h}$. Finally, the immunoreactive proteins were visualized on the film.

\section{In vitro DTX release}

Different DTX formulations $(1 \mathrm{~mL})$ loaded in dialysis bags (MW, 8000) were immersed in $50 \mathrm{~mL}$ of PBS (pH 7.4), PBS (pH 6.8) or $10 \%$ FBS with $0.5 \%$ Tween-80 (v/v), respectively. Next, the drug release system was shaken in water bath at $37^{\circ} \mathrm{C}$ for $72 \mathrm{~h}$ under horizontal shaking at $100 \mathrm{rpm} .100 \mu \mathrm{L}$ dialysis solution outside of the dialysis bag was take out at different time, and $100 \mu \mathrm{L}$ of fresh drug-free medium was added into the dialysis solution outside of the dialysis bag. Finally, the content of DTX in solution was detected by HPLC, and the mobile phase was composed of $45 \%$ ammonium acetate solution $(0.043 \mathrm{~mol} / \mathrm{L})$ and $55 \%$ acetonitrile. The column was eluted at a flow rate of $1 \mathrm{~mL} / \mathrm{min}$ at $25^{\circ} \mathrm{C}$ [44].

\section{Cellular uptake}

Cellular uptake of different biomimetic nanosuspensions was evaluated in bEnd.3 cells, HUVECs, and C6 glioma cells, and the cells were seeded in a 6-well culture plate at a density of $0.5 \times 105$ cells/well. After incubation at $37{ }^{\circ} \mathrm{C}$ for $24 \mathrm{~h}$, different cell membrane-coated biomimetic nanosuspensions were stained with DiI and incubated with the above-listed cells at a concentration of $2 \mu \mathrm{g} / \mathrm{mL}$ for $15 \mathrm{~min}$, after which they were counter-stained with 4',6-diamidino-2-phenylinodole (DAPI, Beyotime) for $5 \mathrm{~min}$. After incubation, the cells were fixed with a $4 \%$ paraformaldehyde solution. Finally, they were fixed with $50 \%$ glycerin. Cell uptake was observed using confocal laser scanning microscopy (CLSM; LSM 880, Zeiss, Germany). For quantitative analysis, $2 \times 10^{4}$ cells were seeded in a 6-well culture plate and cultured for $24 \mathrm{~h}$. After incubation with DiI-labeled biomimetic nanosuspensions for $15 \mathrm{~min}$, the cells were washed three times with cold PBS, trypsinized, resuspended in $300 \mu \mathrm{L}$ of PBS, and analyzed by flow cytometry (FACSAria III, BD, USA).

\section{Homotypic targeting}

Homologous targeting was verified using the uptake of biomimetic nanosuspensions via different types of cancer 
cells. Mouse breast cancer cells (4T1), mouse melanoma cells (B16), human hepatoma cells (HepG2), and C6 glioma cells were seeded in confocal laser dishes at a density of $5 \times 10^{3}$ cells/well. DiI-DNS-C6 DC]m was then added to the cell culture medium for $0.5 \mathrm{~h}$. The uptake of different cells was observed using CLSM.

\section{In vitro penetration of $B B B$ and $B B T B$}

An in vitro BBB model was constructed with bEnd. 3 cells using a Transwell cell culture system. Briefly, bEnd. 3 cells were seeded in the upper chambers of Transwell cell culture plates (Corning, NY, USA) at $1 \times 10^{5}$ cells/well. The integrity of the cultured monolayer model was tested by measuring the trans-endothelial electrical resistance $\left(>200 \Omega \cdot \mathrm{cm}^{2}\right.$ ) using a Millicell-ERS voltohmmeter (Millipore). After the cells were cultured to $100 \%$ confluence, the transendothelial electrical resistance (TEER) of the cell membrane was recorded. When the TEER was over $200 \Omega . \mathrm{cm}^{2}$, C6 cells were seeded in the lower chambers at a density of $1 \times 10^{5}$ cells/well. Next, free DiI, DiI-DNSDCm, DiI-DNS-C6m, and DNS-[C6\&DC]m were added to the upper chamber and cultured for $4 \mathrm{~h}$. Solutions collected from the bottom chamber were assessed using a plate reader, while cell uptake was observed using CLSM. Similarly, HUVECs and C6 cells were used to establish a BBTB model to investigate the penetration ability of the preparations.

The inhibitory effect of DTX on glioma cells in the $\mathrm{BBB}$ and BBTB models in vitro was similarly measured using Transwell chambers [45]. In brief, $1.0 \times 10^{5} \mathrm{bEnd} .3$ cells or HUVECs were seeded onto the upper Transwell chamber. When the cells were overgrown, and the TEER was over $200 \Omega . \mathrm{cm}^{2}$, the lower chamber was seeded with $2 \times 10^{3}$ C6 glioma cells. Next, free DTX, DNS, DNSC6m, DNS-DCm, and DNS-[C6\&DC]m at DTX concentration of $50 \mu \mathrm{g} / \mathrm{mL}$, were added to the upper chamber and cultured for $48 \mathrm{~h}$. The inhibition rate of C6 glioma cell proliferation in the bottom chamber was quantified using the Cell Counting Kit-8 (CCK-8) method.

\section{Immune responses in vitro}

To assess the maturation levels of DCs after different treatments, C6m, DCm and[C6\&DC]m $(50 \mu \mathrm{g} / \mathrm{mL})$ were incubated with DCs for $48 \mathrm{~h}$. The cells were washed three times with PBS and subsequently stained with anti-CD80-PE, and anti-CD86-APC antibodies (Abcam) for $30 \mathrm{~min}$ at $4{ }^{\circ} \mathrm{C}$. After being washed with cold PBS, the cellular fluorescence was detected by flow cytometry. All groups were analyzed in triplicate. Furthermore, to assess the activation levels of $\mathrm{T}$ lymphocytes, $\mathrm{T}$ cells were treated as above mentioned. After cocultured for $48 \mathrm{~h}$, the $\mathrm{T}$ lymphocytes were washed three times with PBS and subsequently stained with anti-CD4-FITC and
anti-CD8-PE antibodies (Abcam) for 30 min at $4{ }^{\circ} \mathrm{C}$. After being washed with cold PBS for thrice, the cellular fluorescence was detected by flow cytometry.

To further evaluate whether the treatment in this study can induce immune response from macrophages, C6 glioma cells were seeded in the lower layer of the Transwell chamber, and RAW264.7 cells were seeded in the upper layer of the chamber at a density of $2 \times 10^{5}$ cells/ well. After $12 \mathrm{~h}, \mathrm{C} 6 \mathrm{~m}, \mathrm{DCm}$, and [C6\&DC]m $(50 \mu \mathrm{g} /$ $\mathrm{mL}$ ) were added to the upper layer of the chamber. In addition, LPS-treated cells were used as a positive control, while blank medium-treated cells were used as the model group. The suspensions of RAW264.7 cells culture media after stimulation were collected after a 48 -h incubation period. The collected samples were tested with mouse IL- 6 , IFN- $\gamma$, and TNF- $\alpha$ ELISA kits, according to the manufacturer's instructions. The inhibitory effect of cytokines on C6 glioma cells was quantified using the CCK- 8 assay.

\section{In vitro cytotoxicity of DNS-[C6\&DC]m on C6 glioma cells} The antitumor activities of DNS, DNS-C6m, DNS-DCm, and DNS-[C6\&DC]m were measured using a standard CCK-8 assay. C6 glioma cells were seeded in a 96-well plate at a density of $5 \times 10^{3}$ cells/well. After incubation for $24 \mathrm{~h}$, different DTX formulations (DNS, DNS-C6m, DNS-DCm, and DNS-[C6\&DC]m) and free PTX were added at concentrations ranging from 1 to $1,000 \mu \mathrm{g} / \mathrm{mL}$ in $100 \mu \mathrm{L}$ of medium, and the plates were incubated at $37{ }^{\circ} \mathrm{C}$ in a $5 \% \mathrm{CO}_{2}$ atmospheric condition for $48 \mathrm{~h}$. After incubation for $48 \mathrm{~h}, 20 \mu \mathrm{L}$ of CCK- 8 solution was added to each well, and the cells were cultured for $2 \mathrm{~h}$. The absorbance of each well was measured at $450 \mathrm{~nm}$ using a microplate reader.

\section{Cell apoptosis assay}

Annexin V-FITC/PI dual staining was used to analyze apoptosis. C6 glioma cells were seeded in a 6-well plate at $1 \times 10^{5}$ cells/well and cultured for $12 \mathrm{~h}$. The cells were then treated with different DTX-loaded formulations (equal to DTX $5 \mu \mathrm{g} / \mathrm{mL}$ ) or free drugs for $48 \mathrm{~h}$. Following $48 \mathrm{~h}$ of incubation, the cells were collected, washed three times with cold PBS, suspended in $300 \mu \mathrm{L}$ of binding buffer, and stained with Annexin V-FITC/PI. Finally, the cells were analyzed using flow cytometry (FACS Aria III, BD, USA). Non-treated cells were used as negative controls, and the experiment was repeated three times.

\section{In vivo brain targeting}

An intracranial glioma-bearing mouse model was established according to previously described procedures [46]. After anesthetizing C6 cells with chloral hydrate (4\%, w/v\%), $2 \mu \mathrm{L}$ of the cells at a density of $2 \times 10^{6}$ were 
injected into the right striatum $(1.8 \mathrm{~mm}$ lateral, $1 \mathrm{~mm}$ longitudinal, and $4 \mathrm{~mm}$ depth) of ICR mice. Using 1,1'-dioctadecyl- 3,3,3',3'-tetramethylindotricarbocyanine iodide (DiR; $1 \mathrm{mg} / \mathrm{kg}$ ) as the fluorescent probe, the mice were intravenously injected with free DiR, DiRDNS-C6m, DiR-DNS-DCm, or DiR-DNS-[C6\&DC]m at day 15 post-inoculation $(n=3)$. At 2,12 , and $24 \mathrm{~h}$, the biodistribution of free DiR and DiR-labeled DTX formulations fluorescence in each group was monitored by an in vivo spectrum imaging system (IVIS ${ }^{\circledR}$ Spectrum, PerkinElmer, USA) using excitation and emission wavelengths of 748 and $780 \mathrm{~nm}$, respectively. For in vitro fluorescence imaging, mice in the DiR-labeled DTX formulations group were sacrificed at $12 \mathrm{~h}$, and their brain tissues and major organs (heart, liver, spleen, lung, and kidney) were collected and visualized using similar imaging parameters. The fluorescence intensity of DiR at each time point was quantitatively evaluated using the ImageJ software.

For tumor distribution analysis, using DiI $(0.5 \mathrm{mg} / \mathrm{kg})$ as the fluorescent probe, the glioma-bearing mice were intravenously injected with free DiI, DiI-DNS-C6m, DiI-DNS-DCm, and DiI-DNS-[C6\&DC]m. After treatment for $4 \mathrm{~h}$, brain tissues were removed and fixed with $4 \%$ paraformaldehyde in the dark for $24 \mathrm{~h}$. DAPI, which was observed at an excitation wavelength of $358 \mathrm{~nm}$ and emission wavelength of $461 \mathrm{~nm}$, was used to stain the nucleus. Finally, the distribution of nanosuspensions in each brain tissue was observed using an inverted fluorescence microscope.

\section{In vivo immune activation}

To evaluate the immune response in vivo, the gliomabearing ICR mice were divided into six experimental groups and immunized three times at intervals of 1 week by intravenous injection with PBS (Model), DNS, DNSC6m, DNS-DCm, [C6\&DC]m, and DNS-[C6\&DC]m at an equal amount of DTX $(20 \mathrm{mg} / \mathrm{kg})$. After 14 days, the posterior ocular venous plexus blood, which was isolated from mice, was centrifuged (4000 rpm; $10 \mathrm{~min}$ ) to obtain serum. The different cytokines (TNF- $\alpha$, IFN- $\gamma$, and IL-6) in serum were then quantitatively analyzed. Briefly, serum was diluted three times with the standard diluent. Cytokines were detected using an ELISA kit according to the manufacturer's protocol. Thereafter, the spleen and draining lymph nodes were dissected and collected. The tissue was fixed with $4 \%$ paraformaldehyde, embedded in paraffin, and cut into thin sections. Immunofluorescence and immunohistochemical (IHC) staining were conducted on both lymphoid and spleen tissues to determine the levels of CD4 and CD8 receptors and TNF- $\alpha$, as well as to observe the activation of the immune system of glioma-bearing mice under different treatments.

\section{In vivo anti-glioma efficacy}

C6 glioma-bearing ICR mice were randomly divided into six treatment groups (six mice/group): PBS, DTX, DNS, DNS-C6m, DNS-DCm, and DNS-[C6\&DC]m. The mice were intravenously injected with the corresponding DTX formulations at a DTX dosage of $20 \mathrm{mg} / \mathrm{kg}$ every 2 days (Fig. 8A). After administration, brain glioma was evaluated via magnetic resonance imaging (MRI) (PharmaScan $70 \mathrm{~T} / 16$, Bruke, US), and the body weight of mice was measured every 2 days after treatment. Mice survival period was also recorded when death or pathologic events occurred. After 20 days of administration, three mice from each group were randomly selected and euthanized, and the brains were collected and fixed at $48 \mathrm{~h}$ with $4 \%$ paraformaldehyde for H\&E, TUNEL, and Caspase-3 staining to determine the degree of tumor cell apoptosis. Brain tissue was stained with IHC to determine the expression of CD31 receptors in neovascularization, which is related to tumor cell proliferation.

\section{Preliminary safety evaluation in vivo and in vitro}

We investigated the in vivo biological safety of biomimetic nanosuspensions. Normal male mice were randomly divided into six groups and intravenously injected with $200 \mu \mathrm{L}$ of normal PBS, free DTX, DNS, DNS-C6m, DNS-DCm, and DNS-[C6\&DC]m. Fifteen days later, all mice were euthanized, and blood cells and serum biochemical indexes were examined. Further, the heart, liver, spleen, lung, kidney, and brain were removed for histology via $H \& E$ staining.

\section{Statistical analysis}

All experiments were conducted in triplicate and expressed as mean \pm standard deviation. Statistical significance was analyzed using SPSS 19.0 software (IBM Corp., Armonk, NY, USA). One-way analysis of variance with a post-hoc Tukey's test was used to determine significant differences between datasets. Statistical significance levels were set at ${ }^{*} \mathrm{p}<0.05$, ${ }^{* *} \mathrm{p}<0.01$, and ${ }^{* * * *} \mathrm{p}<0.001$, ns, not significant, as indicated in Additional file 1: Fig. S1.

\section{Results and discussion \\ Characterization of DNS}

The process of preparing DNS is illustrated in Fig. 2A. The ultrasonic precipitation method was simple and reproducible. Ethanol can be removed via magnetic stirring, which helps to improve the biological safety of the preparation, and the occurrence of any adverse reactions can be reduced. TEM images demonstrated that DNS was uniform in size and round in shape (Fig. 2B). As shown by the XRD curves (Additional file 1: Fig. S1A), DTX and SDC demonstrate strong crystal diffraction of 


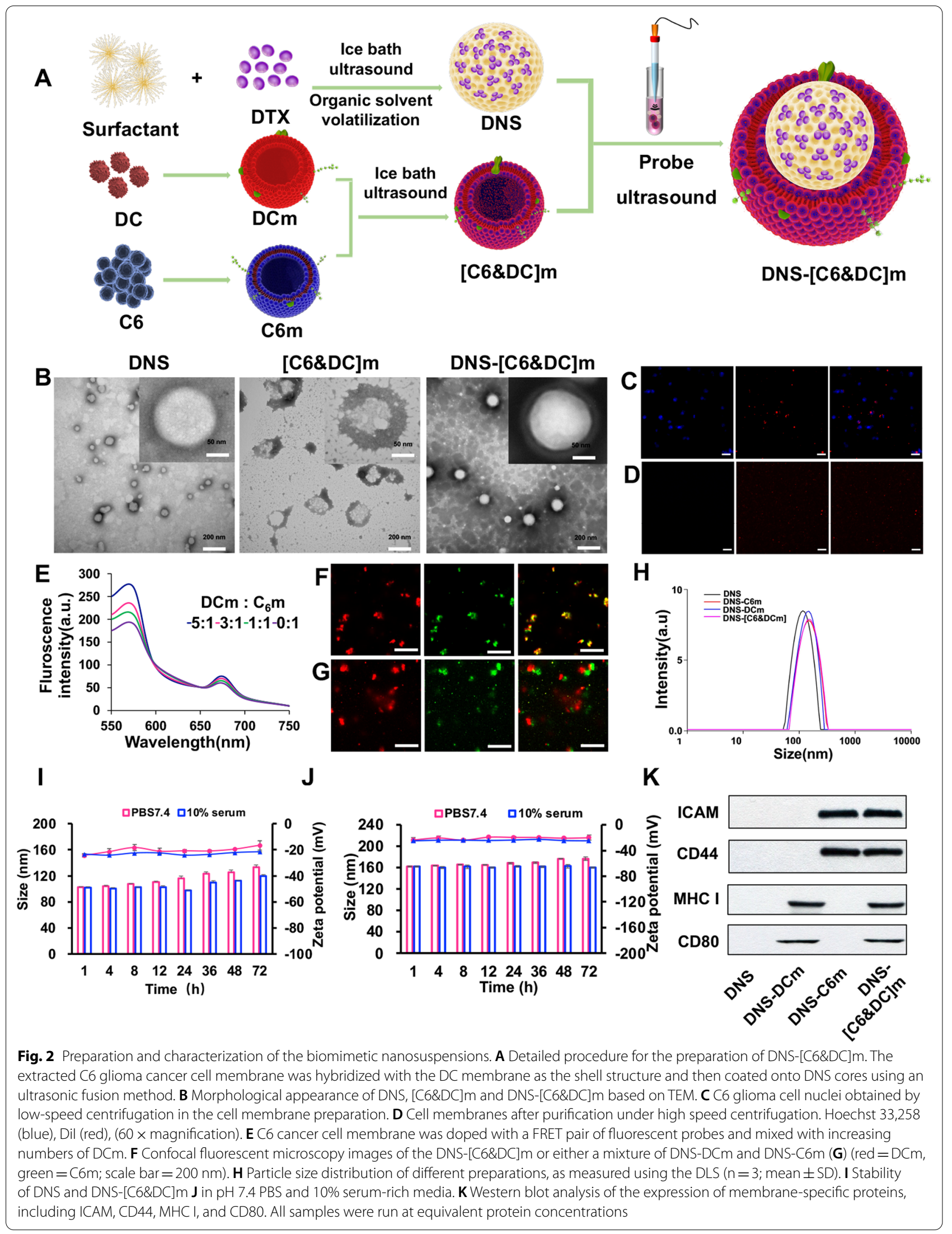


HPMC E5, and lecithin does not have a diffraction peak, indicating that DTX and SDC exist within the crystal structure. However, HPMC E5 and lecithin are amorphous. The physical mixture showed the same crystal diffraction peak, indicating that simple physical mixing cannot destroy the crystal structures of DTX and SDC. Furthermore, the crystal diffraction peaks in the nanosuspension completely disappeared, showing that DTX exists in an amorphous form in DNS. The same sample was analyzed using differential scanning calorimetry (Additional file 1: Fig. S1B). We discovered that the DTX endothermic peak disappeared in DNS, while the SDC endothermic peak moved forward. DTX is an amorphous structure in DNS, which is consistent with our X-ray diffraction results. The results of FTIR scanning (Additional file 1: Fig. S1C) validated that the drug did not react with excipients in the solution and existed independently. These characterization results validate the successful preparation of the DTX nanosuspension.

\section{Membrane fusion study}

To verify that the extracted C6 cell membrane did not contain tumor nucleus-related genetic material, laser confocal microscopy was used to observe the separation of the nuclear membrane from C6 glioma cells. The nucleus was collected via centrifugation, and a portion of the cell membrane was precipitated. The cell nucleus was removed, the cell membrane was collected, and the nuclear membrane was separated (Fig. 2C, D).

As the successful fusion of DCm and C6m was crucial for the drug and antigen delivery of DNS-[C6\&DCm], cell fusion was first investigated. To test the fusion of the DC and C6 membranes, a C6 membrane was doped with two different dyes that constituted a FRET pair [47]. It was observed that the fluorescence resonance occurred at $578 \mathrm{~nm}$, and as the amount of DC membrane increased, there was a recovery of fluorescence at approximately a $675-\mathrm{nm}$ emission wavelength, indicating the fusion of the two membrane materials, weakening FRET interactions in the original C6 membrane (Fig. 2E). Next, laser confocal colocalization imaging was used to further verify the fusion of the two cell membranes. C6m and $\mathrm{DCm}$ were mixed in a protein weight ratio of 1:1. The DCm labeled with the red fluorescent dye (DiI) was fused with $\mathrm{C} 6 \mathrm{~m}$, which was labeled with a green fluorescent dye (DiD). When a diluted solution of DNS-[C6\&DC]m was viewed under confocal microscope, significant colocalization of fluorescent signals was observed (Fig. 2F). In contrast, a mixture of DNS-C6m and DNS-DCm fabricated with individual fluorescently labeled membranes exhibited distinct red and green punctates. It was further demonstrated that $\mathrm{C} 6 \mathrm{~m}$ and $\mathrm{DCm}$ were retained on the DNS-[C6\&DC]m at a ratio nearly identical to the $1: 1$ input (Fig. 2G). These results indicate that it was indeed possible to fuse the two types of cell membranes and incorporate materials of both membranes into the same nanosuspensions.

\section{Preparation and characterization of DNS-[C6\&DC]m}

TEM imaging showed that DNS-[C6\&DC]m were spherical. A layer of membrane structure was observed on the surface of the nanoparticles, which had a core-shell structure (Fig. 2B). Particle size is an important parameter associated with nanosuspensions, which helps to determine the physical and chemical properties of each particle [48]. DLS was used to compare the sizes of the DNS and DNS-[C6\&DC]m. As shown in Fig. 2H, DNS exhibited an original size of approximately $144 \mathrm{~nm}$, which increased by $10 \mathrm{~nm}$ after coating [C6\&DC]m. This particle size is suitable for molecules in the blood to enter tissue, exist close to cell surface receptors, and promote intracellular transport $[49,50]$, as observed in our TEM detection results. Additionally, the zeta potential changed from -20 to $-33 \mathrm{mV}$ (Additional file 1: Fig. S2), which was more conducive to maintaining the stability of the nanosystem. Moreover, the increase in zeta potential can help promote tumor penetration and lysosome escape, which enhances the delivery of brain-targeted drugs. Since stability is a prerequisite for further application of DNS-[C6\&DC] $\mathrm{m}$ in vivo, the agglomerations of the biomimetic nanosystems in PBS and PBS with $10 \%$ FBS were evaluated within $72 \mathrm{~h}$ at $37^{\circ} \mathrm{C}$ to mimic the stability at in vivo conditions. Compared with DNS, DNS-[C6\&DC] $\mathrm{m}$ maintained good dimensional stability and a negative zeta potential in neutral PBS or PBS containing $10 \%$ FBS (Fig. 2I, J), implying that DNS-[C6\&DC]m is able to prolong the blood circulation time. These results suggest that the hybrid membrane can significantly improve the stability of DNS and prolong circulation times, which are attributed to a shielding effect that is based on cell membrane coverage. The drug loading efficiency (LE) and encapsulation efficiency (EE) of DNS-[C6\&DC]m were $20 \pm 0.4 \%$ and $82.13 \pm 0.1 \%$, respectively. The BCA assay revealed an optimized membrane-to-DNS ratio of 1:1 (Additional file 1: Fig. S3).

The protein components of the DNS, DNS-C6m, DNSDCm, and DNS-[C6\&DC]m were analyzed by sodium dodecyl sulfate-polyacrylamide gel electrophoresis (SDS-PAGE). The results showed that the original protein compositions of $\mathrm{DCm}$ and $\mathrm{C} 6 \mathrm{~m}$ were retained in DNS-[C6\&DC]m (Additional file 1: Fig. S4A). The protein contents of all samples were determined using a BCA kit before western blotting (Additional file 1: Fig. S4B). Compared to the prepared hybrid cell membrane, we found less protein loss due to cell membrane resuspension and ultrasound during the process of preparation. 
Western blotting analysis for specific protein markers was performed Normally, CD44 and ICAM are related to adhesion and invasion between C6 glioma cells [7, 51, 52]. As shown in Fig. 2K, CD44 and ICAM were expressed on DNS-C6m and DNS-[C6\&DC]m, which could generate specific recognition and binding between DNS-[C6\&DC]m and glioma cells. In addition, mature DCs mediate $\mathrm{T}$ cell activation and proliferation through interactions between ligands (MHC I and CD80) on the $\mathrm{DC}$ cell membrane and receptors on the surface of $\mathrm{T}$ cells [53]. The MHC I and CD80 protein bands were observed in the DNS-DCm and DNS-[C6\&DC]m groups, but not in DNS and DNS-C6m. The results confirmed that the MHC I and CD80 molecules on the nanoparticles retained their $\mathrm{T}$ cell binding moieties. Gray value analysis (Additional file 1: Fig. S4C-F) demonstrated that the protein content of DNS-[C6\&DC]m was slightly reduced, which could have occurred during the process of preparation. These results further indicated that DNS[C6\&DC]m could potentially serve as a nanoscale NDDS for drug delivery and antigen presentation.

\section{In vitro release profile}

To mimic the release profiles of DTX in vivo, the drug release kinetics of DNS-[C6\&DC]m and DNS were measured at $37^{\circ} \mathrm{C}$ for $72 \mathrm{~h}$ in medium at $\mathrm{pH} 6.8$ to represent the acidic environment of tumor, at $\mathrm{pH} 7.4$ for a normal physiological environment, and at 10\% FBS for blood circulation environment $[32,54]$. The release results for the different drug formulations are shown in Additional file 1: Fig. S5. DNS showed a similar release behavior in $\mathrm{PBS}$ at both $\mathrm{pH}$ 7.4 (Additional file 1: Fig. S4A) and $\mathrm{pH}$ 6.8 (Additional file 1: Fig. S4B), while an obvious initial burst profile was observed in 10\% FBS (Additional file 1: Fig. S4C). Interestingly, DNS-[C6\&DC]m only released quickly in $\mathrm{PBS}$ at $\mathrm{pH}$ 6.8. These results suggest that the stability and controlled release behavior of DNS improves after cell membrane coating, effectively satisfying the drug concentration requirements of chemotherapy. It has been speculated that the mode of entry of the drug into the body can prolong its circulation time.

\section{Cellular uptake of DNS-[C6\&DC]m and the underlying mechanism}

It is well recognized that cellular uptake is a prerequisite for drug delivery. As bEnd.3, HUVECs, and C6 cells are key components of the BBB and BBTB, biomimetic nanosuspension cellular uptake and internalization by these cells were investigated. As shown in Fig. 3, we first studied the targeting and uptake abilities of biomimetic nanosuspensions in C6 glioma cells. Our results demonstrated that endocytosis of different biomimetic nanosuspensions was notably influenced by the type of membrane.
The DNS-[C6\&DC]m could be taken up by C6 glioma cells at high rates, demonstrating that DNS-[C6\&DC]m retains highly specific self-targeting adhesion to $\mathrm{C} 6$ glioma cells. To validate the penetrating ability of the biomimetic nanosuspensions into tumor tissues, the cellular uptake of HUVECs, which are similar to tumor neovascular endothelial cells, was studied. DiI-DNS-C6m and DiI-DNS-[C6\&DC]m demonstrated stronger intracellular fluorescence in HUVECs compared to free DiI, indicating that $\mathrm{C} 6 \mathrm{~m}$ can penetrate the $\mathrm{BBB}$ and deliver drugs to tumors by targeting tumor neovascularization. Finally, confocal microscopy and flow cytometry demonstrated that the intracellular fluorescence intensity of bEend.3 cells treated with DiI-DNS-DCM was much lower than that of the cells treated with DiI-DNS-[C6\&DC]m, indicating that DNS-[C6\&DC]m could be better internalized by bEend. 3 cells. In addition, the fluorescence intensity of bEend. 3 cells in the DNS-C6m group was similar to that in the DNS-[C6\&DC]m group, suggesting that the better endocytosis of bEend. 3 cells to DNS-[C6\&DC]m was the result of $\mathrm{C} 6$ membrane-mediated homologous targeting ability.

\section{In vitro $\mathrm{BBB}$ and $\mathrm{BBTB}$ model transportation of DNS-[C6\&DC]m}

Transwell models were used to evaluate the ability of DNS-[C6\&DC]m to cross the BBB and BBTB in vitro. Monolayer culture in a Transwell with bEnd. 3 cells or HUVECs in the upper chamber and C6 cells in the lower chamber are commonly used in in vitro models for brain delivery studies [55]. An in vitro BBB model with barrier function was established using bEnd.3/C6 glioma cells. The TEER value was over $200 \Omega \mathrm{cm}^{2}$, indicating that a complete BBB structure was successfully established. Confocal microscopy results revealed that the penetration abilities of DNS-[C6\&DC]m and DNS-C6m were stronger than those of the other groups, and the fluorescence intensity of the bottom chamber solution was the highest (Fig. 4A, C). There was a significant difference compared to free DiI and DiI-DNS-DCm, which proved the importance of $\mathrm{C} 6$ in crossing the $\mathrm{BBB}$. The HUVEC/C6 cell co-culture model was used as the BBTB, and the resistance value was $321.5 \Omega \cdot \mathrm{cm}^{2}$. Among all groups, DNS-[C6\&DC]m showed the strongest targeting capability, further indicating that $\mathrm{C} 6 \mathrm{~m}$ can penetrate the BBB and potentially deliver drugs to tumors (Fig. 4B, E). The apoptosis rates of $\mathrm{C} 6$ cells in the BBB and BBTB were determined using the CCK- 8 assay. The cell viabilities of DNS-[C6\&DC]m, DNS-C6m, DNS-DCm, and DTX in the BBB were $51.13 \%, 71.67 \%, 84.21 \%$, and 93.39\%, respectively (Fig. 4D), and those in the BBTB were $57.37 \%, 74.57 \%, 84.93 \%$, and $92.50 \%$, respectively (Fig. 4F). DNS-[C6\&DC]m demonstrated the highest 


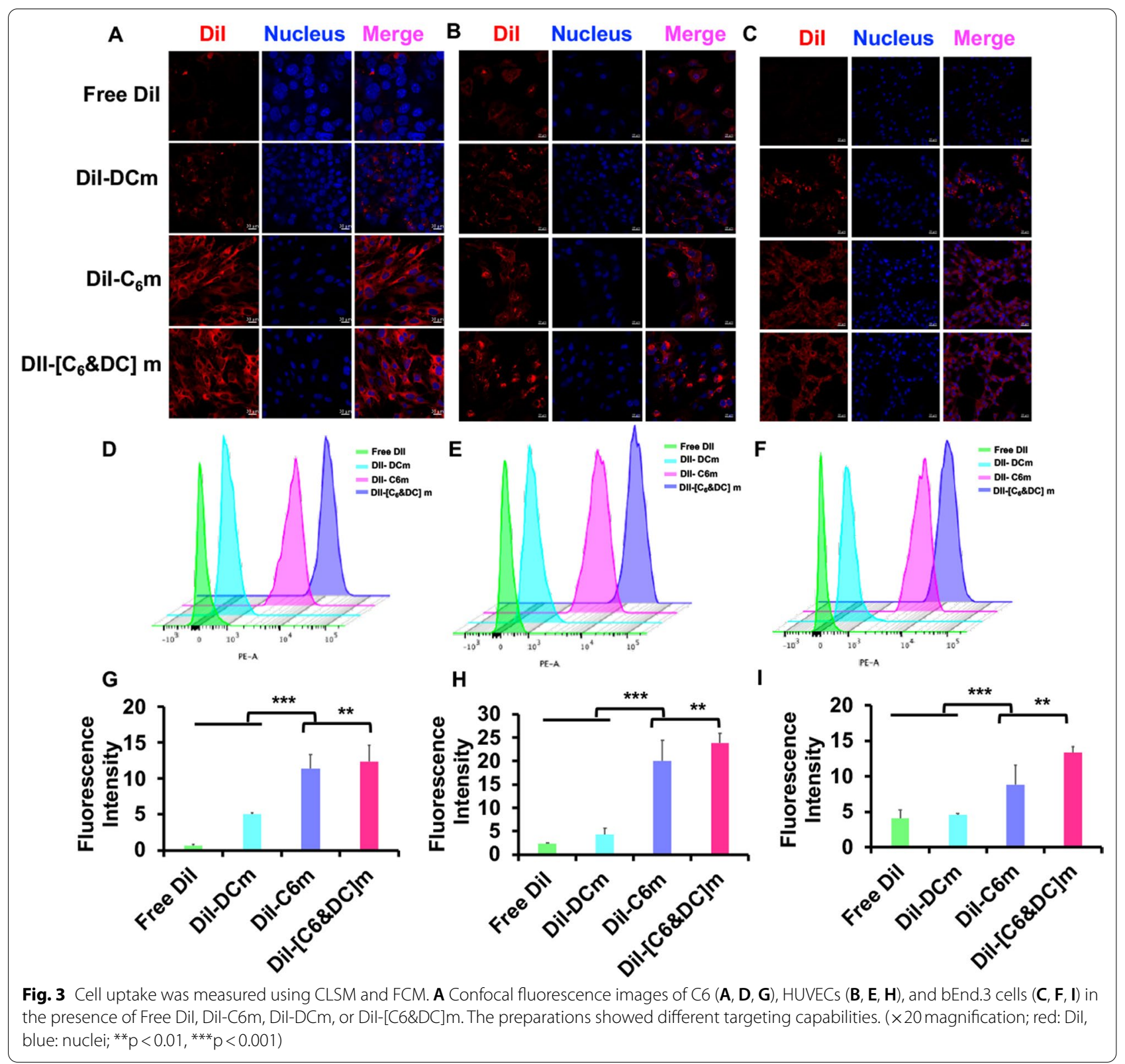

inhibition of cancer cell proliferation. It is reasonable to assume that more DNS-[C6\&DC]m could pass through the $\mathrm{BBB}$ and $\mathrm{BBTB}$ model, reach tumor sites, and lead to better tumor cell killing effects.

\section{In vitro homologous targeting study}

To verify the homotypic targeting effect of DNS[C6\&DC]m, CLSM was used to detect the endocytosis effect of different cells on nanoparticles. The results shown in Additional file 1: Fig. S6 show that the fluorescence intensities of B16, HepG2, and 4T1 cells were much weaker than that of the C6 cells, further demonstrating that DNS-[C6\&DC]m has homology targeting and specific recognition functions, which proves that the selective targeting properties of DNS-[C6\&DC]m are not suitable for other cancer cells.

\section{In vitro immune cells priming and tumor cell inhibition}

The mature of DCs was the key impetus for T cells activation. The hallmarks of DC cell maturation are the high expression of antigen presenting molecules (MHC-I and MHC-II) and stimulating factors (CD80, CD86, etc.) [56, 57]. We assessed the in vitro immunostimulatory activity of DCs after the treatment with C6m, DCm, [C6\&DC] 


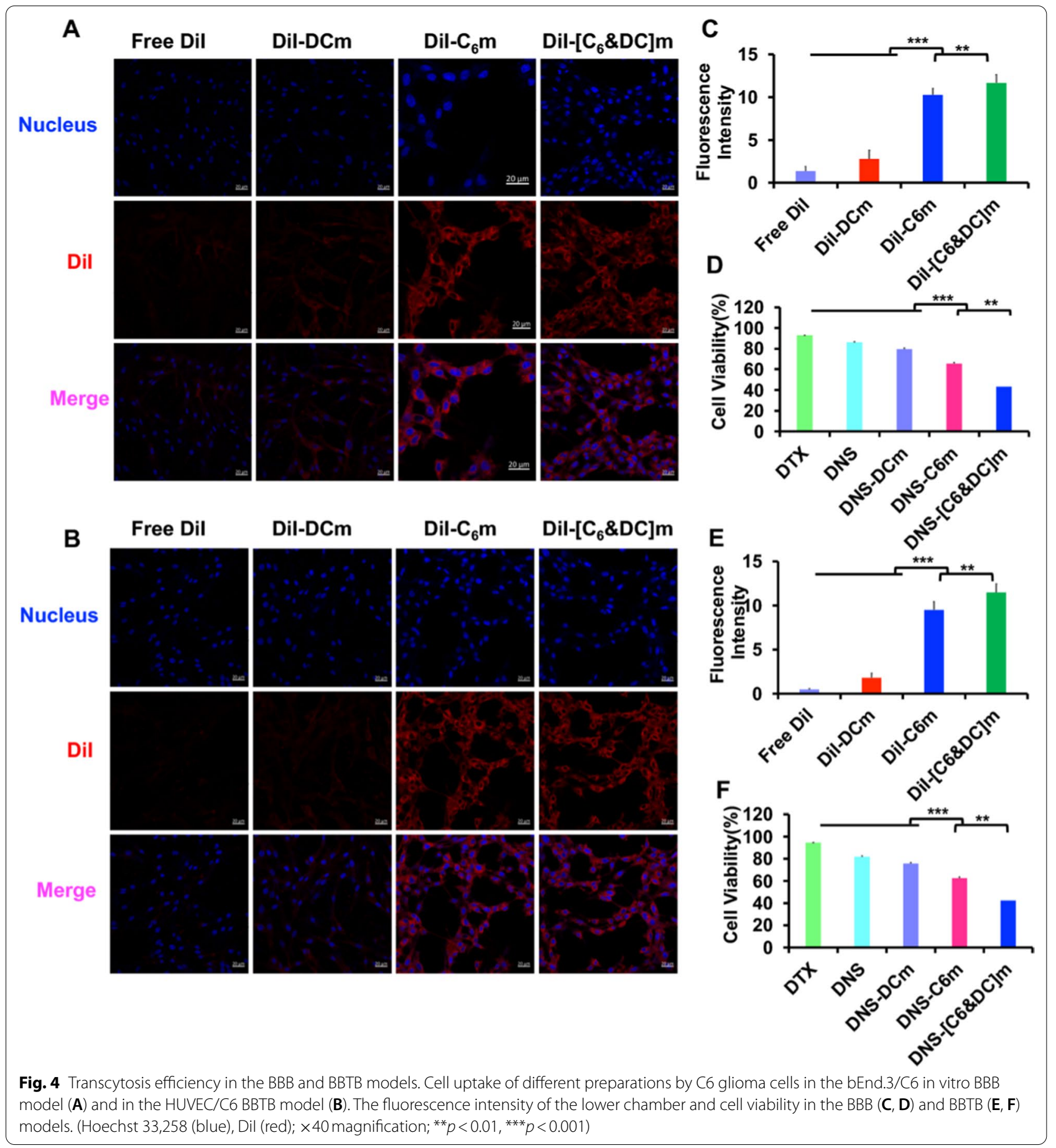

$\mathrm{m}$, and the results found that the percentage of $\mathrm{CD} 80^{+}$ and $\mathrm{CD}^{2} 6^{+} \mathrm{DCs}$ after the treatment with [C6\&DC]m was obviously higher than that of other groups (Fig. 5A, $\mathrm{B}$ and Additional file 1: Fig. S7). Although C6m contained innate tumor antigens, its efficiency of $\mathrm{T}$ cell activation seemed to be similar or even lower than that of DMs.
This result is possibly related to the specific recognition of DCs by T cells.

Provided that tumor antigens could be processed and expressed on $[C 6 \& D C] m$ during membrane fusion, $[C 6 \& D C] \mathrm{m}$ could present tumor antigens to $\mathrm{T}$ cells and directly active $\mathrm{T}$ cells owing to the partial inclusion 


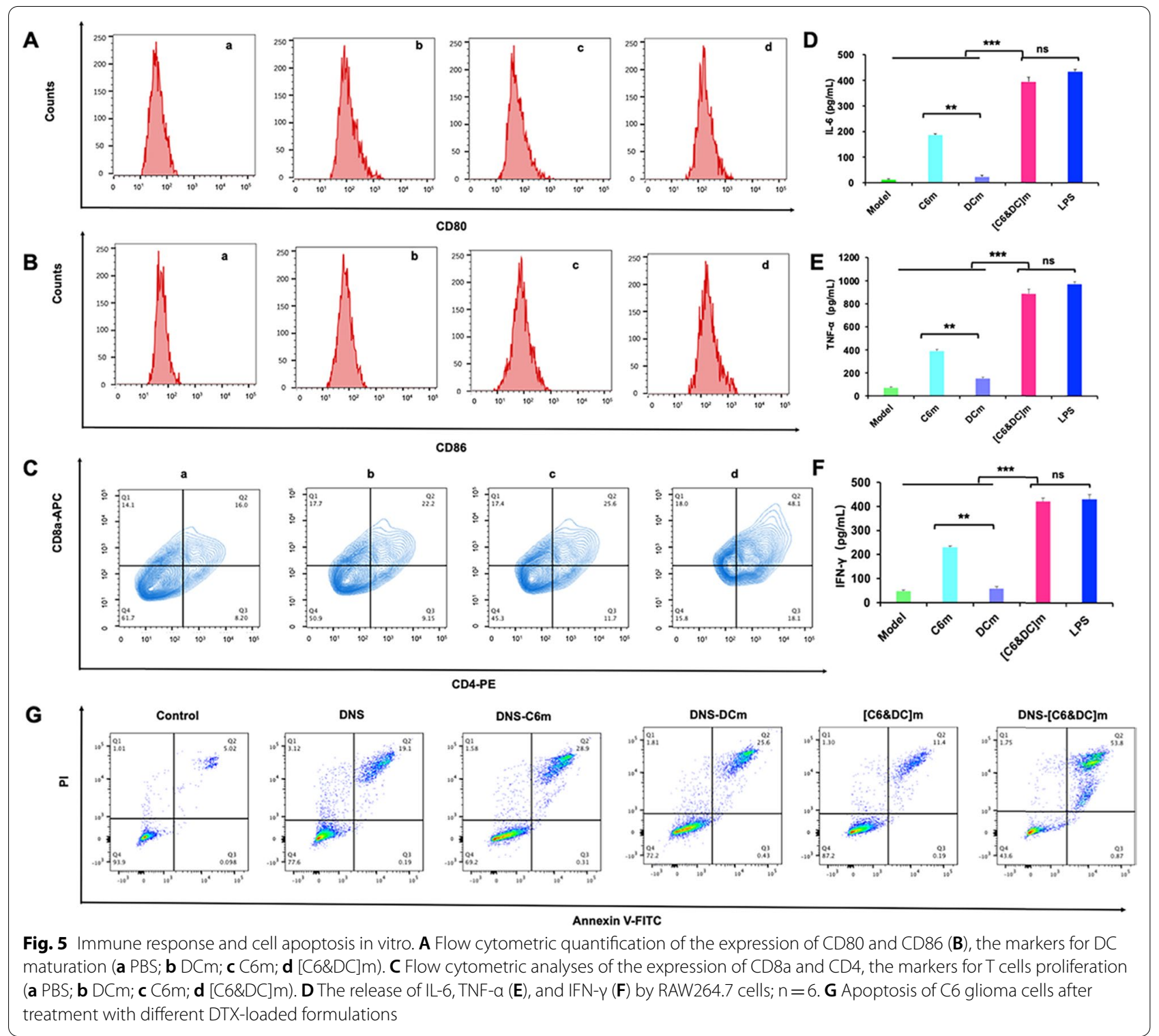

of $\mathrm{DCm}$ fragments in [C6\&DC]m. Like tumor cells, $[C 6 \& D C] \mathrm{m}$ can be recognized by DCs and consequently, the matured DCs can serve as APCs to present antigens to $\mathrm{T}$ cells. The demonstration of these two of direct and indirect pathways are evaluated via flow cytometry. It is well known that $\mathrm{CD}^{+} \mathrm{T}$ lymphocytes (CTLs) and $\mathrm{CD} 4$ + helper $\mathrm{T}$ cells play a vital role in regulating the immune response $[58,59]$, we measured the expression of CD8 and CD4 on the cytomembrane of T cells (from mouse splenocytes) via flow cytometry. After $48 \mathrm{~h}$ coincubation, the percentage of $\mathrm{CD}^{+}$CTLs and $\mathrm{CD} 4^{+}$ helper $\mathrm{T}$ cells was dramatically increased (Fig. 5C). In comparison, much less increment was observed in the DNS-C6m and DNS-DCm treated groups. The result indicates that DNS-[C6\&DC]m were more powerful to promote a majority of the $\mathrm{T}$ cells proliferation.

Macrophages are highly plastic cells that adopt a variety of activation states in response to stimuli that are found in the body environment. In this study, DNS-[C6\&DC] $\mathrm{m}$ are inherited from two parent cell lines, hybrid membranes could confer a continuous source of tumor antigens, which can be presented for activating macrophages to release cytokines, including IL- 6 , TNF- $\alpha$, and IFN- $\gamma$ $[60,61]$. The inflammatory cytokines released by immune cells can help induce the immune system to kill tumor cells, directly or indirectly, thus inhibiting tumor cell growth [62]. To measure the cytokines secreted by RAW264.7 cells after stimulation with $[C 6 \& D C] m$, the 
immune-related cytokines, including IL- 6 , TNF- $\alpha$, and IFN- $\gamma$, were measured using ELISA. After $48 \mathrm{~h}$ of coincubation, as shown in Fig. 5D-F, the levels of inflammatory cytokines in the $[C 6 \& D C] \mathrm{m}$ group were significantly higher than those in the other groups $(P<0.001)$, which was similar to that of the LPS group. In comparison, a much smaller increment was observed in the C6m- and DCM-treated groups. These results indicate that the hybrid membranes of DCm and C6m were more powerful in stimulating microphages than single C6m or DCm. In the fusion process, DCs can capture and process the tumor antigens of C6s, and then present a whole array of tumor antigens to microphages and further promote the release of TNF- $\alpha$, IFN- $\gamma$, and IL- 6 cytokines.

To monitor the effect of released cytokines, the inhibitory effect of cytokines on C6 cells was quantified using the CCK-8 assay. As shown in Additional file 1: Fig. S8, the cell viability of the model group was close to $100 \%$. Compared to the C6m and DCm groups, $[C 6 \& D C] \mathrm{m}$ significantly inhibited tumor cell proliferation $(P<0.001)$, indicating that $[C 6 \& D C] m$ could effectively stimulate macrophages to release cytokines (TNF- $\alpha$, IL- 6 , and IFN$\gamma)$. TNF- $\alpha$ and IFN- $\gamma$ can bind to their corresponding receptors and then move into the cell. Following uptake by target cell lysosome, cytokines facilitate the reduction of lysosomal stability, resulting in the leakage of various enzymes, which could lead to the lysis of C6 cells. Furthermore, IL- 6 can change the glucose metabolism of glioma cells, lower intracellular $\mathrm{pH}$, and cause cancer cell death, further indicating that the fusion of $\mathrm{C} 6 \mathrm{~m}$ and $\mathrm{DCm}$ is necessary for stimulating cells to produce an immune response.

\section{In vitro cytotoxicity of DNS-[C6\&DC]m on C6 glioma cells}

As shown in Additional file 1: Fig. S9, DNS-[C6\&DC] $\mathrm{m}$ effectively inhibited the growth of $\mathrm{C} 6$ glioma cells. With increasing drug concentration, the inhibitory effect of each group on C6 cells was found to be significantly enhanced. DNS-[C6\&DC]m induced the strongest growth inhibition in C6 cells, with an $\mathrm{IC}_{50}$ of $7.78 \mu \mathrm{g} /$ $\mathrm{mL}$, which was much lower than that of DTX $(29.29 \mu \mathrm{g} /$ $\mathrm{mL}$ ). The apoptosis analysis via flow cytometry revealed that DNS-[C6\&DC]m induced the highest apoptotic rate of $54.26 \pm 2.32 \%$ (early and late apoptosis) in C6 cells, whereas the rates were $29.52 \pm 4.143 \%, 29.31 \pm 2.181 \%$, $19.30 \pm 5.021 \%$, and $12.85 \pm 2.820 \%$ for DNS-C6m, DNSDCm, DNS, and [C6\&DC]m, respectively (Fig. 5G). These results showed that DNS-[C6\&DC]m significantly enhanced DTX cytotoxicity and apoptosis in C6 glioma cells, which may be related to the increased cell uptake efficiency and the combination of drug toxicity and immunogenic killing effect, indicating the potential of DNS-[C6\&DC]m as an advanced platform for multiple modes of anti-glioma therapy.

\section{In vivo biodistribution}

The brain tumor targetability of DNS-[C6\&DC]m was evaluated in an intracranial glioma-bearing mouse model. We first monitored the in vivo biodistribution of DiR-labeled DTX formulations after intravenous administration in glioma-bearing mice models using an in vivo spectrum imaging system (IVIS ${ }^{\circledR}$ Spectrum, PerkinElmer, USA). As shown in Fig. 6A, compared with the free DiR or DiR-DNS-DCm-treated mice. a strong DiR fluorescence was observed in the DiR-DNS-C6m and DiR-DNS[C6\&DC]m group, localized to brain tumor locations. Notably, DiR-DNS-[C6\&DC]m presented a significantly stronger capability of brain targeting in the glioma-bearing mice than any other groups. As the time was extended to $24 \mathrm{~h}$, more DiR-DNS-[C6\&DC]m migrated to C6 glioma cells. Furthermore, compared to the free DiR group, DNS-[C6\&DC]m demonstrated an increasing trend of the liver accumulation of DNS-[C6\&DC]m at first and then a decreasing trend, indicating that the membranecoated nanomedicine can significantly prolong time of accumulation at the tumor site. Three dimensional CT scan fluorescence imaging results depicted an accumulation of DNS-[C6\&DC]m at the tumor site (Fig. 6B), which further supports the precise brain targeting of DNS-[C6\&DC]m. These data suggest that the inherent homotypic binding phenomenon among tumor cells resulted in an enhanced brain-tumor-targeting effect of the DiR-DNS-[C6\&DC]m, which were able to target the intracranial glioma cells, as further confirmed by a quantitative ROI analysis (Fig. 6C).

We also collected the hearts, livers, spleens, lungs, kidneys, and brains of mice treated with different DiR-labeled DTX formulations and investigated their distribution in each organ (Fig. 6D). Strong DiRDNS[C6\&DC] $\mathrm{m}$ and DiR-DNS-C6m fluorescence were observed in the brain and localized to brain tumor locations. Quantitative analysis of the brain tissue further confirmed the brain-targeting effect of DNS[C6\&DC]m (Fig. 6E). Additionally, consistent with previous reports, DiR-DNS[C6\&DC]m accumulated in the liver because it is involved in the metabolism and

(See figure on next page.)

Fig. 6 In vivo distribution of DiR-DNS-[C6\&DC]m. A In vivo fluorescence imaging of intracranial glioma-bearing mice treated with DiR-DNS-[C6\&DC] $\mathrm{m}$ at different time points. B A three-dimensional brain CT tumor localization scan. $\mathbf{C}$ In vivo quantification of DiR-DNS-[C6\&DC]m in brain distribution. D Biodistribution of different DiR-labelled biomimetic nanosuspensions across different organs. $\mathbf{E}$ In vitro quantification of different DiR-labelled biomimetic nanosuspensions in isolated brain. F Distribution of brain tissue in vitro (DAPI: blue, Dil: red; $20 \times$ magnification) 


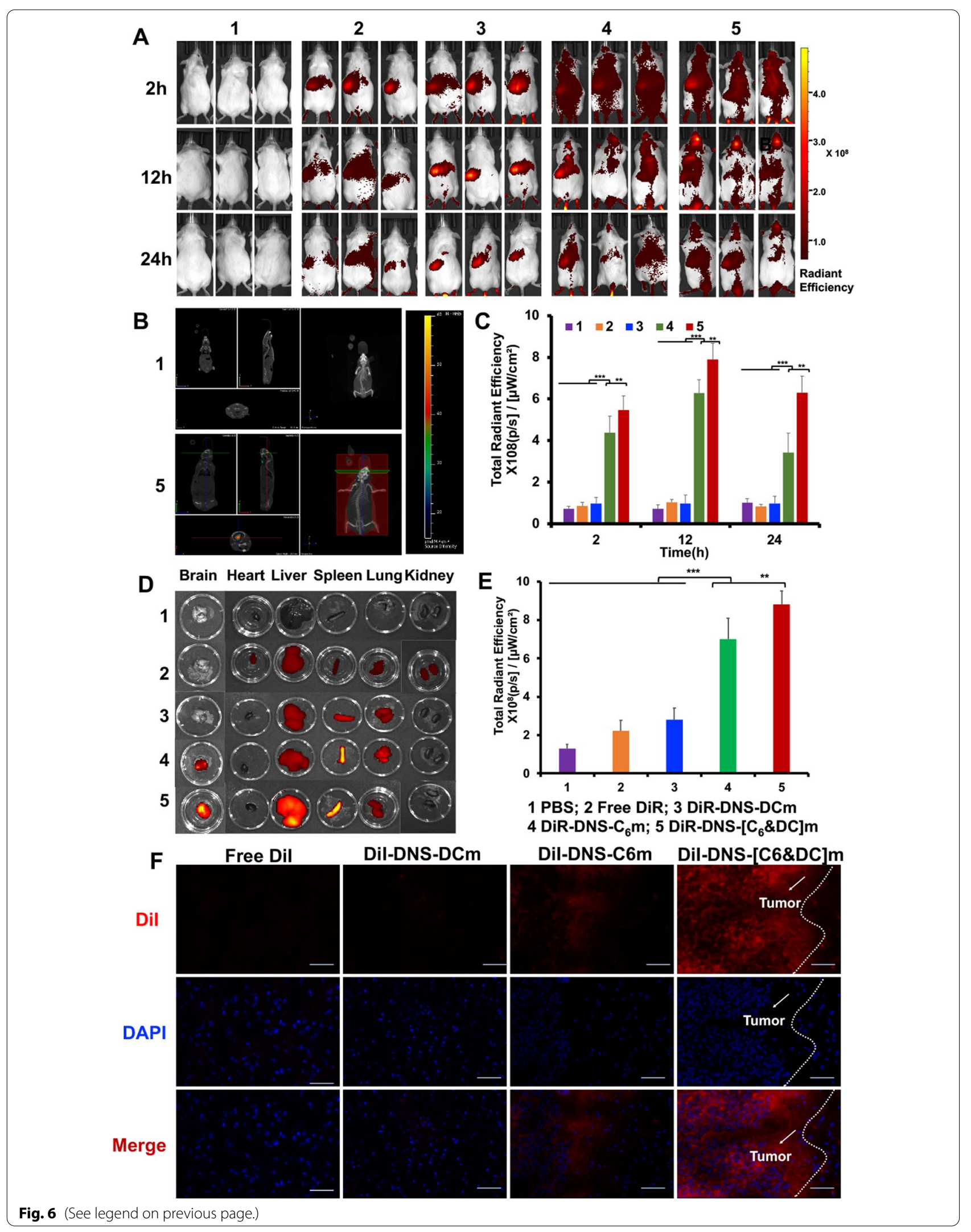


elimination of nanoparticles [42]. Further, the spleen is the largest immune organ, based on the natural antigen presentation ability of DCs, and tumor-associated antigens are presented to the spleen by DNS-[C6\&DC]m for immune-activating functions.

The brain tissue of mice injected with DiI-labeled biomimetic nanosuspensions was sectioned. As shown in Fig. 6F, free DiI did not enter the tumor tissues; however, DNS-C6m and DNS-[C6\&DC]m were distributed in the tumor tissues, confirming their homologous targeting effect. Taken together, these data confirm our hypothesis that DNS-[C6\&DC]m has C6-like tumor-homing characteristics, which facilitate homotypic-driven DNS$[C 6 \& D C] m$ recruitment at the glioma site.

\section{In vivo immune activation effect}

Next, we evaluated the antitumor immune responses elicited by the injection of DNS-[C6\&DC]m in vivo. $\mathrm{CD}^{+}$CTLs are the main force that kills cancer cells in our immune design, and $\mathrm{CD} 4^{+} \mathrm{T}$ cells can help CTLs proliferate and increase their toxicity towards tumors $[63,64]$. We measured the expression of CD8 and CD4 at tumor sites with different treatments via IHC and immunofluorescence staining to investigate the direct immune

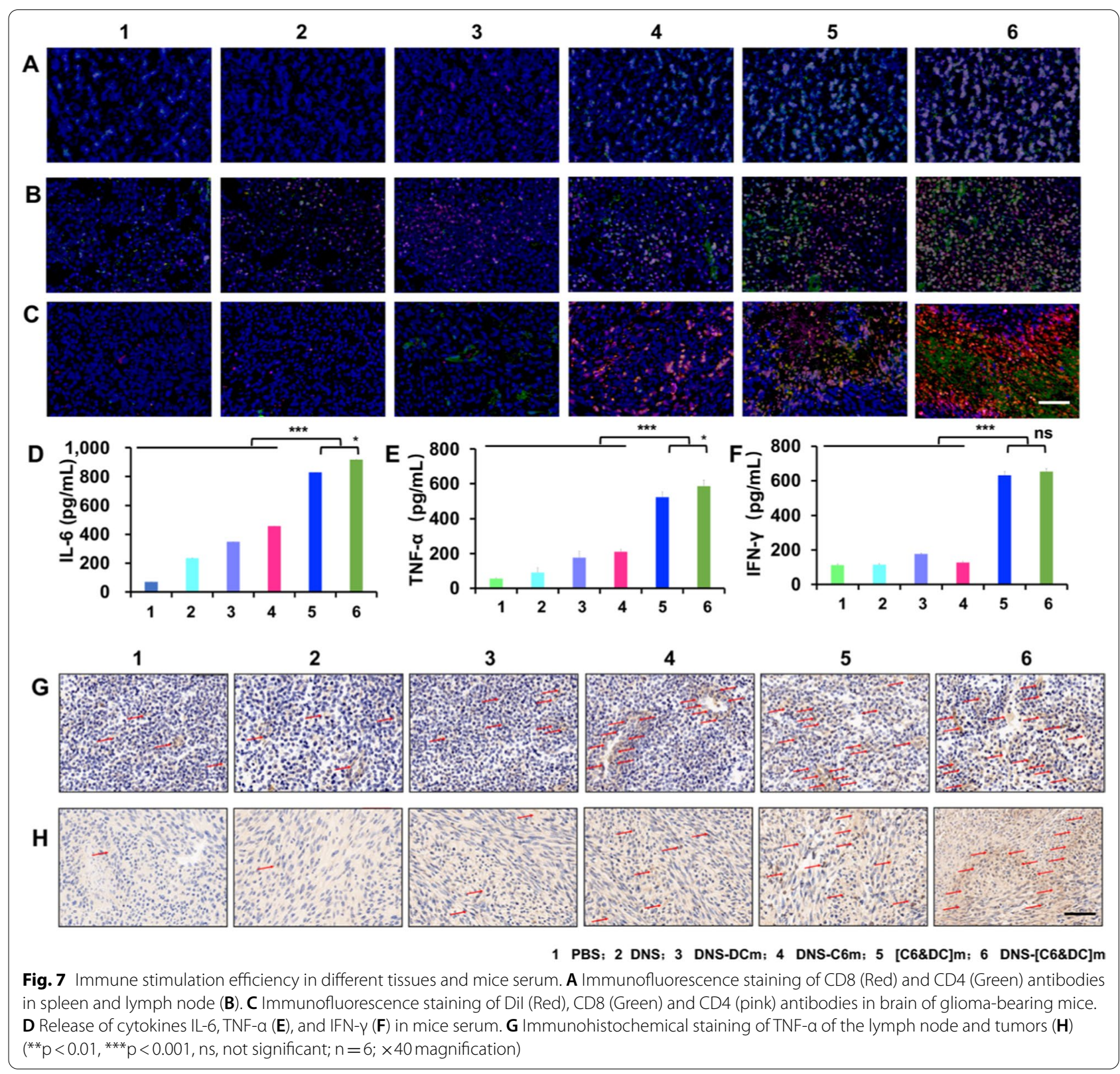


response pathway. As shown in Fig. 7A, compared to the PBS group, the number of $\mathrm{CD}^{+}$and $\mathrm{CD} 4^{+} \mathrm{T}$ cells from the spleen in the [C6\&DC]m and DNS-[C6\&DC] $\mathrm{m}$ groups increased significantly. In comparison, a much smaller increase was observed in the DNS-C6m- and DNS-DCm-treated groups. Although DNS-C6m contains tumor antigens from $\mathrm{C} 6 \mathrm{~m}$, its efficacy in $\mathrm{T}$ cell activation seemed to be similar or even lower than that of DNS, which fully proves that DNS-[C6\&DC]m relies on the antigen presentation effect of $\mathrm{DCm}$ to induce an immune response from the body. In the fusion process, DNS- $[C 6 \& D C] \mathrm{m}$ can retain the tumor antigens of tumor cells, and mature DCs stimulated by tumor-associated antigens can promote the proliferation and activation of $\mathrm{CD}^{+}$and $\mathrm{CD}^{+} \mathrm{T}$ lymphocytes. Remarkably, a similar phenomenon was observed in the lymph nodes (Fig. 7B). Furthermore, it is important to find accurate colocalization in the glioma site of the biodistribution of DiIlabeled DNS-[C6\&DC]m and cytotoxic T cells (Fig. 7C), further indicating that DNS-[C6\&DC]m can not only accurately cross the $\mathrm{BBB}$ and target the glioma site for drug delivery directly, but can also effectively stimulate the immune system to produce cytotoxic $\mathrm{T}$ cells for indirect immunogenicity inhibition of the blood circulation on the tumor [65].

Cytokine secretion is a characteristic marker of $\mathrm{T}$ cell activation. Inspired by the activation of microphages in vitro, the release of TNF- $\alpha$, IFN- $\gamma$, and IL- 6 in mouse serum was examined using ELISA after different treatments. As shown in Fig. 7D-F, the expression of these cytokines in the DNS-[C6\&DC]m group was higher than that in the other groups. Notably, despite the fact that DNS-[C6\&DC]m and DNS-C6m both contain tumorassociated antigens, the levels of these three cytokines were significantly different $(P<0.001)$, which proved that DNS-[C6\&DC]m relies on the antigen presentation effect of DCm to induce an immune response. The delivery of antigens to macrophages affects the microenvironment of the immune system, which may potentially lead to immunogenic cell damage. IHC was used to observe TNF- $\alpha$ expression within the lymph nodes and tumor sites (Fig. 7G, H). Upregulation of TNF- $\alpha$ expression was observed after DNS-[C6\&DC]m treatment, which was consistent with the in vitro results, indicating that the DNS-[C6\&DC]m treatment promoted macrophage activity and induced comparable TNF- $\alpha$ production. TNF- $\alpha$ binds to its corresponding receptors and then moves into the cell. Following uptake by the target cancer cell lysosome, the cytokine reduces lysosomal stability, leading to the lysis of C6 cells.

In summary, the in vivo immune experimental results demonstrated that DNS-[C6\&DC]m could effectively strengthen the immune response and inhibit the immune escape of tumor cells. Further, DNS-[C6\&DC]m could stimulate microphages to release cytokines, which bind to the corresponding receptors and then move into the cell. Following uptake by the target cell lysosome, cytokines reduce lysosomal stability, leading to the leakage of various enzymes and C6 cell lysis. Additionally, DNS-[C6\&DC]m could enhance the ability of $\mathrm{T}$ lymphocytes to capture antigens. Naive $\mathrm{T}$ cells differentiate into $\mathrm{CD} 8^{+}$and $\mathrm{CD} 4^{+} \mathrm{T}$ cells and indirectly interfere with tumor growth [66].

\section{In vivo anti-glioma efficacy}

To explore the therapeutic efficacy of DNS-[C6\&DC]m in vivo, we monitored the contours of the different glioma sites in C6 glioma-bearing mice after DNS-[C6\&DC]m, DNS-C6m, DNS-DCm, DNS, free DTX, and PBS treatment using MRI. As shown in Fig. 8B, glioma cells in the PBS group grew rapidly and exhibited the largest tumors. For the free DTX and DNS groups, a malignant situation similar to that of the PBS group was observed, and the glioma proliferated significantly with time. In contrast, DNS-[C6\&DC]m and DNS-C6m groups showed weak MRI signals, and glioma growth was obviously suppressed, indicating that these formulations could suppress the rapid growth of the glioma more effectively through accurate delivery of DTX to the brain tumor site as a result of the homotypic targeting abilities of $C 6 \mathrm{~m}$. High drug-carrying capacity significantly improved the drug concentration at the targeted sites. Notably, better antitumor efficacy was observed in the DNS-[C6\&DC]m group than in the DNS-C6m group, possibly due to the immune response induced by $\mathrm{DCm}$. The combination of drug delivery and antigen delivery resulted in a better chemoimmunotherapeutic effect in gliomas.

Further, we performed histological analysis to examine the therapeutic effects of the different treatments. H\&E staining revealed typical glioma malignancy with dense glioma cell features in both the PBS, DTX, DNS, and DNS-DCm groups. In comparison, glioma cell density was significantly lower in DNS-[C6\&DC]m-treated mice than in the mice of the other groups, demonstrating that

(See figure on next page.)

Fig. 8 Therapeutic efficacy of DNS-[C6\&DC]m in glioma-bearing mice. A Schematic illustration of the administration regimenfor DNS-[C6\&DC]m therapy. B MRI of normal and glioma-bearing mice after different treatments. $\mathbf{C H}$ HE staining of the tumor tissues. D Immunohistochemical staining of CD31 and Caspase-3 (E) of the tumors. F TUNEL staining analysis of the tumors ( $\times 40$ magnification). G Quantification using Image of TUNEL apopotosis after different administration ( ${ }^{* *} \mathrm{p}<0.01,{ }^{* * *} \mathrm{p}<0.001$, ns, not significant). $\mathbf{H}$ Kaplan-Meier survival curve of glioma-bearing mice after drug treatment. I Body weight changes of mice in different treatment groups 
A

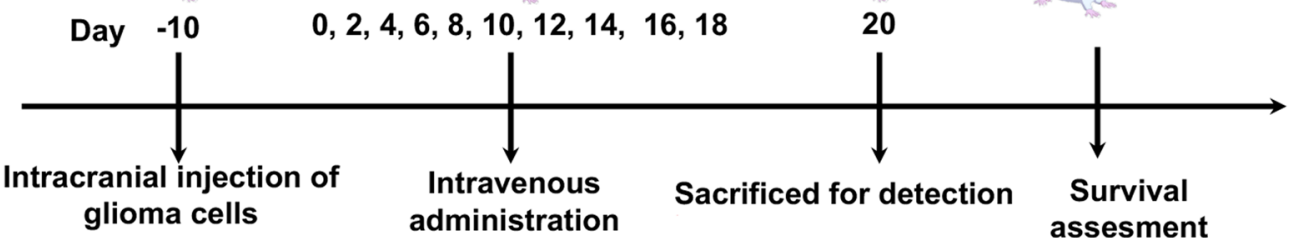

B
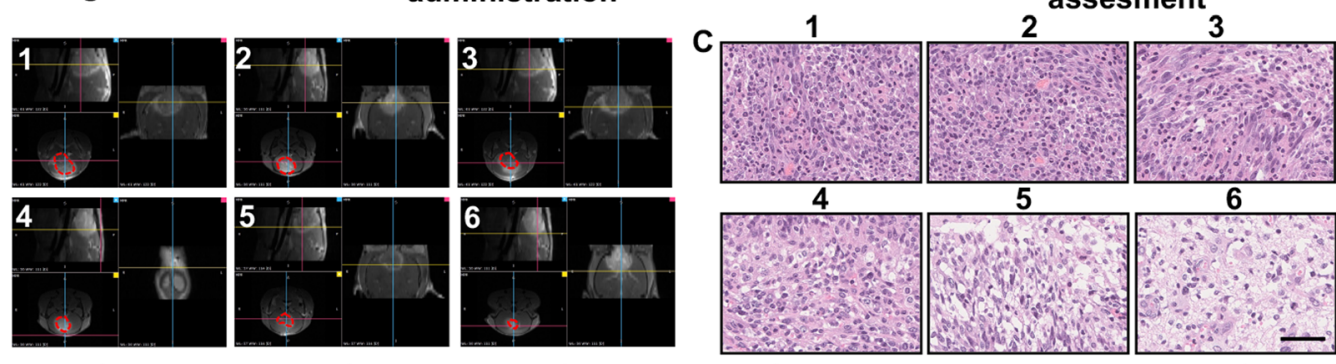

D

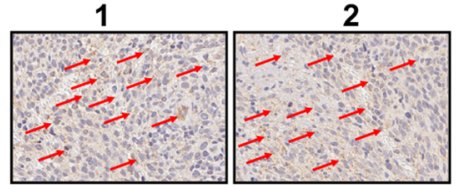

3
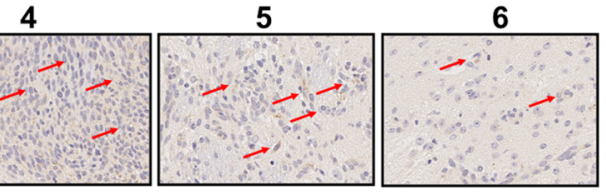

E
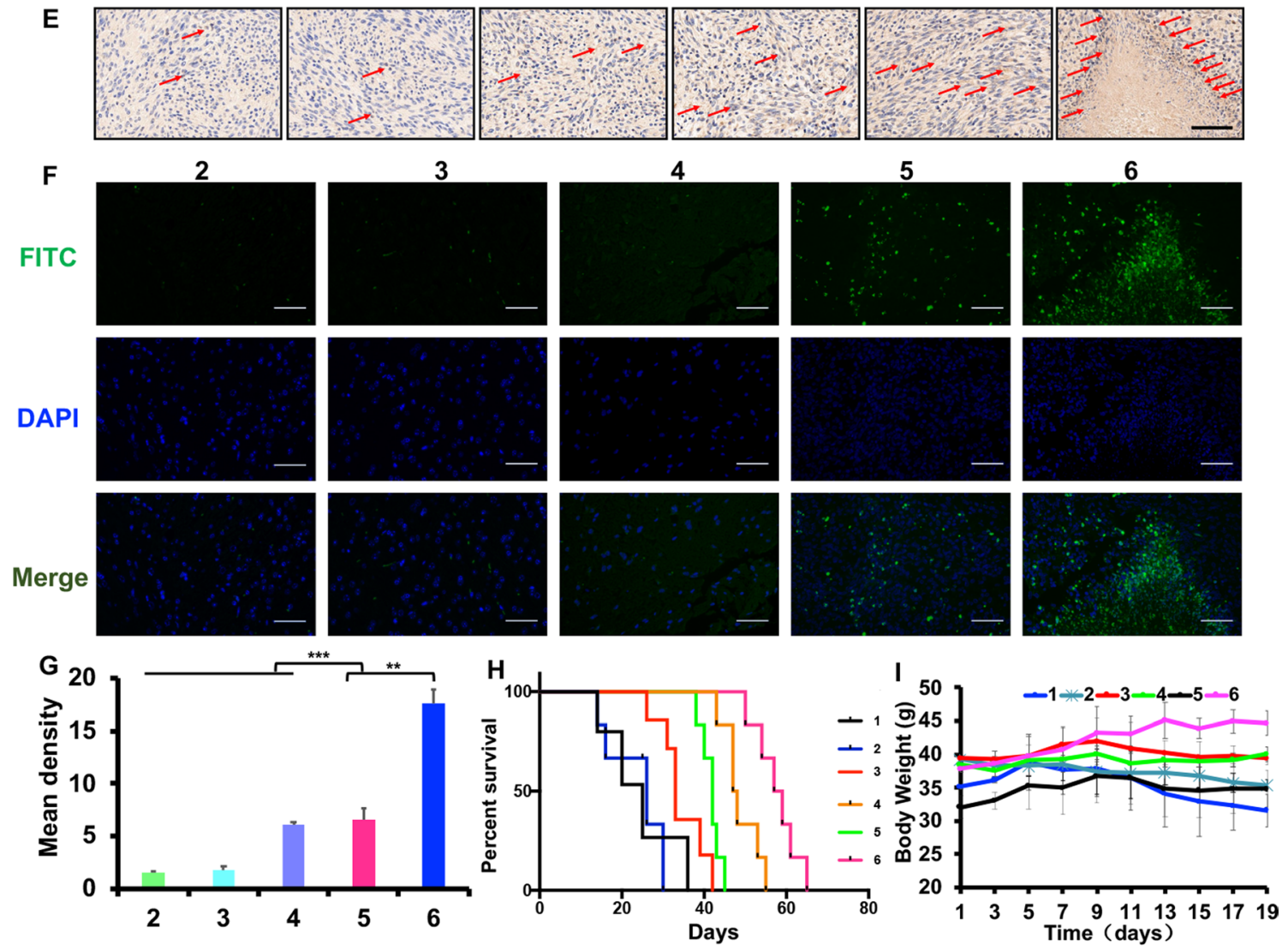

1 PBS; 2 DTX; 3 DNS; 4 DNS-DCm; 5 DNS-C6m; 6 DNS-[C 6 \&DC]m

Fig. 8 (See legend on previous page.) 
DNS-[C6\&DC]m effectively inhibited tumor proliferation (Fig. 8C). CD31 is a marker of tumor angiogenesis [67]. IHC staining of brain tissue was conducted to examine the expression of CD31 receptors in neovascularization related to tumor cell proliferation. The relatively high brain tumor CD31 expression after DNS-[C6\&DC] $\mathrm{m}$ treatment highlights DNS-[C6\&DC]m suppression of malignant progression in glioma (Fig. 8D).

Apoptosis of brain tumor tissue was investigated by performing caspase-3 staining and TUNEL staining (Fig. 8E-G). Cell apoptosis was more evident in the DNS$[C 6 \& D C] m$ group than in any other group, indicating that DNS-[C6\&DC]m could penetrate more deeply into the glioma tissues via drug delivery, and the activation of the immune system for immunotherapy killed more viable cells than any other treatment. Kaplan-Meier survival curves (Fig. $8 \mathrm{H}$ ) demonstrated that treatment with DNS-[C6\&DC]m significantly prolonged the survival duration of glioma-bearing mice. The survival duration of the mice treated with DNS-[C6\&DC]m (65 days) was significantly longer than that of the mice treated with PBS (36 days), free DTX (37 days), DNS (42 days), DNS-DCm (45 days), and DNS-C6m (55 days). In terms of physiological status, decreased body weight was observed in PBS- and DTX-treated mice, while a relatively lower rate of body weight decrease was observed in mice receiving DNS-[C6\&DC]m treatment (Fig. 8I). In DTX-treated mice, this decreased body weight may have been a result of systemic side effects of DTX resulting from non-specific circulation of chemotherapeutic drug in the blood [68]. This phenomenon is consistent with DNS-[C6\&DC] $m$ enhancing the intracranial glioma targetability and therapeutic efficacy of DTX, consequently ameliorating DTX side effects.

\section{Safety of biomimetic drug-delivery systems in vitro and in vivo}

An ideal nanocarrier needs to not only have suitable physical and chemical properties but also minimal toxicity and high biocompatibility. The in vivo biosafety of the biomimetic nanosuspensions was evaluated using hematological and histopathological analyses. Evaluation of uric acid, aspartate aminotransferase, alanine aminotransferase, and creatinine levels in the blood showed that DTX and DNS affect liver and kidney function. As shown in Fig. 9B-E, the mice treated with DNS-C6m, DNS-DCm, and DNS-[C6\&DC]m were relatively stable. We also measured the levels of platelets and RBCs in the blood. Compared to the indices of the mice in DTX and DNS groups, the indices of the DNS-C6m-, DNS-DCm-, and DNS-[C6\&DC]m-treated mice were found to be relatively stable. In contrast, mice treated with the free drugs DTX and DNS had increased levels of platelets and RBCs during the treatment period (Fig. 9F). Additionally, after the administration of DTX, DNS, DNS-C6m, DNS$\mathrm{DCm}$, and DNS-[C6\&DC]m, no obvious pathological damage to the heart, liver, spleen, lung, kidney, and brain of the mice was observed (Fig. 9G). The histological and blood biochemistry results confirmed the lower toxicity and better in vivo safety of DNS-[C6\&DC]m, possibly due to the enhanced stability, minimized RES uptake, and controlled drug release profile.

\section{Conclusions}

In summary, we have successfully established a hybrid cell membrane-coated drug nanosuspension platform for multiple modes of anticancer therapy via drug and antigen delivery. As nature-inspired biomimetic nanosuspensions, DNS-[C6\&DC]m are expected to maintain the excellent biological functions of both $\mathrm{C} 6$ and DC cells. Our observations suggest that the homologous targeting of biological characteristics of cancer cell membranes provides a key impetus for precise targeted delivery of drugs, which increases drug accumulation and further enhances the efficacy of the loaded chemotherapeutic drug in tumor sites of the intracranial glioma model. At the same time, due to the professional antigen presentation characteristic of $\mathrm{DCm}$, the platform presents antigens to the body's immune system for efficient downstream immune activation. The synergistic effects of chemotherapy and immunotherapy increase the anticancer effect. For clinical translation, we predict that the hybrid membrane coating technology presented in this study can be further expanded to other cell types for different biomedical applications. By fusing the homologous cancer membrane with immune-related cells, diverse therapeutic nanoparticles can be freely camouflaged according to the disease and drug needs to achieve efficient drug delivery and strengthen immune response. Further, this platform may be generalized for the delivery of various drugs with low solubility or high toxicity, especially those that need to be administered intravenously, such as hydroxycamptothecin and paclitaxel. Overall, our research demonstrates the outstanding therapeutic efficiency of DNS-[C6\&DC]m for glioma treatment, which has the potential to treat a wide range of cancers through precise tumor-targeted drug delivery and antigen presentation, and represents a promising approach to individualized multiple-mode therapeutics for cancer therapy. 

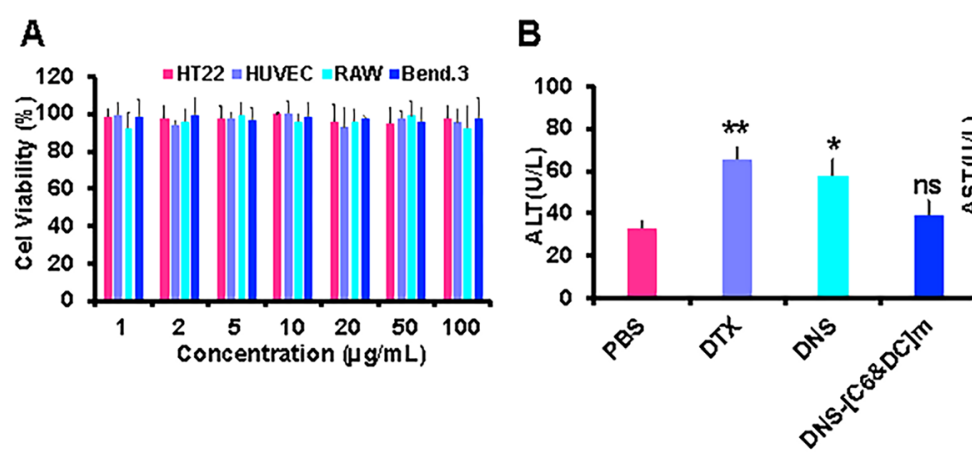

\section{C}

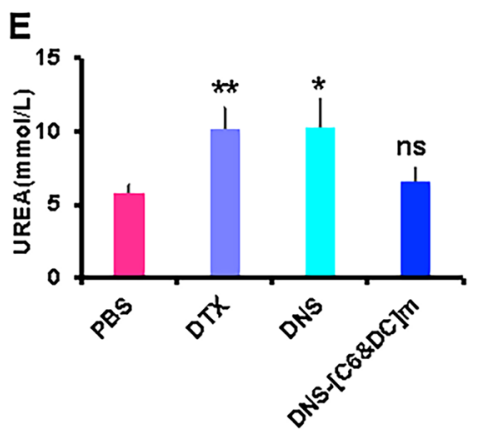

$\mathbf{F}$
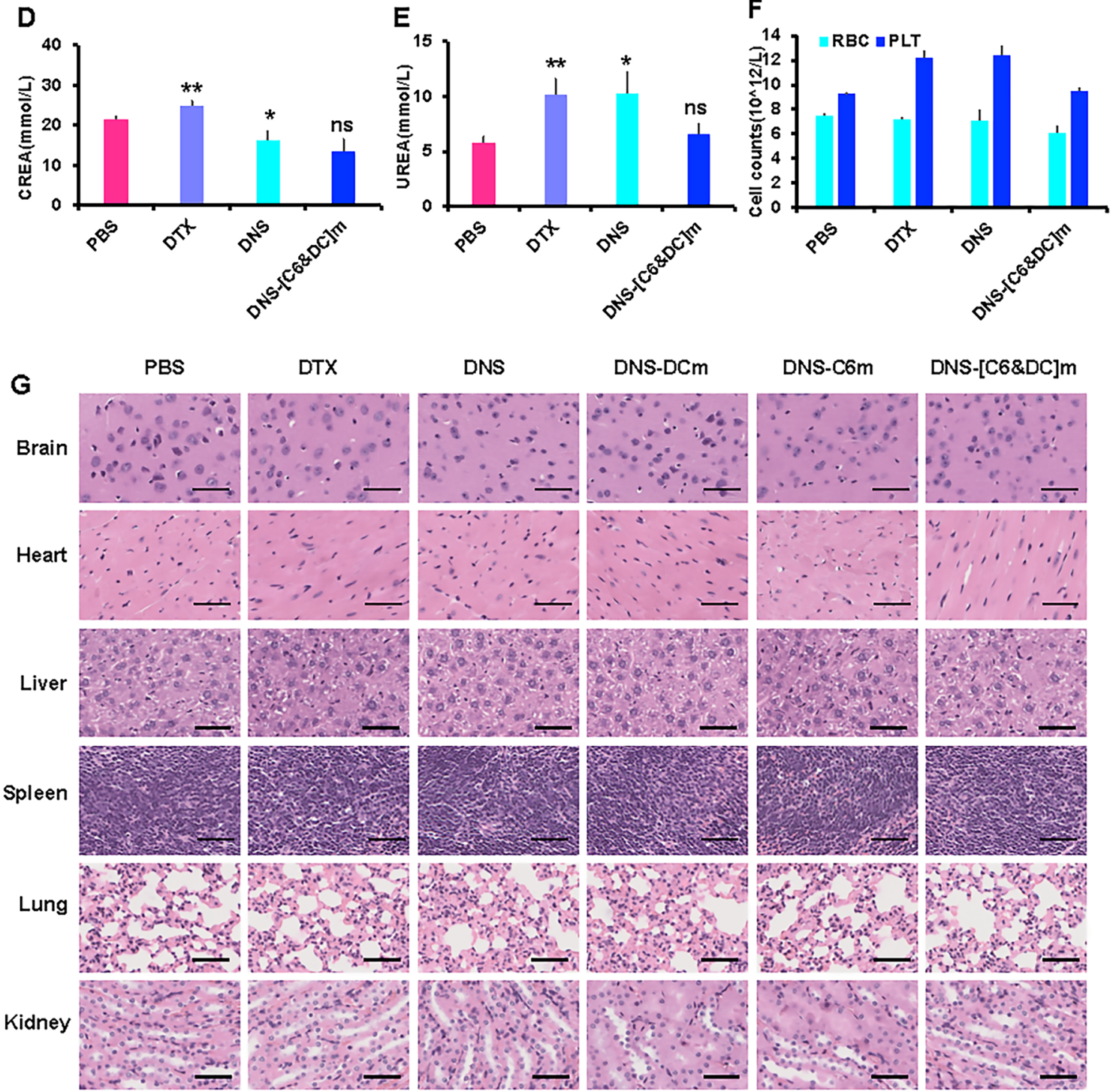

Fig. 9 Preliminary safety evaluation. A Cell viabilities of HT22 cells, HUVECs, RAW cells, and bEnd.3 cells incubated for $24 \mathrm{~h}$ with different concentrations of empty formulations. Data are presented as means $\pm S D(n=6)$. B Levels of liver and kidney function markers, including UREA, AST (C), ALT (D), and CREA (E). F Levels of blood cells, including DC and platelets. $\mathbf{G}$ Histological examination of major organs derived from mice after treatment ( $\times 40$ magnification). $\left({ }^{* *} P<0.01,{ }^{*} P<0.05\right.$, ns, not significant) 


\section{Supplementary Information}

The online version contains supplementary material available at https://doi. org/10.1186/s12951-021-01110-0.

Additional file 1: Fig. S1.Characterization of DNS. (A) X-ray diffraction patterns of different components in the DNS. (B) Scanning of different components in the DNS using differential scanning calorimetry. (C) FTIR spectra of different components in DNS. Fig. S2. Zeta potential of different preparations, as measured using the DLS. Fig. S3. Quantification of total proteins on DNS-[C6\&DC]m by BCA assay after incubating different amount of [C6\&DC] $m$ to DNS at different membrane-to-DNS weight ratios (w/w). Fig. S4. (A) The membrane protein of the biomimetic nanosuspensions was determined via SDS-PAGE. (B) The protein contents of cancer cell membranes and biomimetic nanosuspensions were determined using the BCA kit. (C) Gray value of membrane-specific proteins ICAM, CD44 (D), MHC I(E), and CD80 (F). Fig. S5 Release profile of free DTX, DNS, and DNS-[C6\&DC]m in (A) PBS at pH 7.4, (B) PBS at pH 6.8, or (C) $10 \%$ FBS at $37^{\circ} \mathrm{C}$. Error bars: mean \pm SD $(n=3)$. Fig. $\mathbf{6} 6$ Cell uptake of the biomimetic nanosuspensions by different cancer cells was investigated using CLSM. The intracellular uptake of DNS-[C6\&DC]m in B16 (A), HepG2 (B), 4T1 (C), and C6 glioma (D) cells. The nuclei were stained with Hoechst 33258 (blue), and the DNS-[C6\&DC]m were labeled with Dil (red) $(40 \times$ magnification). Fig. S7. The percentage of DCs maturation. ( ${ }^{*} p<0.05,{ }^{* *} p<0.01,{ }^{* * *} p<0.001$, ns, not significant; $n=6$ ). Fig. S8. The inhibitory effect of cytokines on C6 glioma cells. $\left({ }^{*} p<0.05\right.$, ${ }^{* *} p$ $<0.01,{ }^{* *} p<0.001$, ns, not significant; $n=6$ ). Fig. S9. The inhibitory effect of different DTX-loaded formulations on C6 glioma cells. Error bars: mean \pm $\operatorname{SD}(n=6)$.

\section{Acknowledgements}

This work was supported by the National Natural Science Foundation of China (Grant No. 82073783) and the Beijing Natural Science Foundation (Grant No. 7212160).

\section{Authors' contributions}

CG and YY conceived the idea and designed the experiments; $W H, Y C, Y F$, and MC performed the experiments. GY analyzed the data. YW, MY, ZL, and WG provided suggestions and technical support for this research. $Y W, Y Y, W H$, and YC wrote the manuscript. All authors contributed to the general discussion. All authors read and approved the final manuscript.

\section{Declarations}

\section{Ethics approval and consent to participate}

All procedures involving the care and handling of animals were carried out with the approval of the Animal Care and Use Ethics Committee of the Beijing Institute of Pharmacology and Toxicology (Beijing, China). This committee also approved all animal-related experiments in the current study (No. IACUC-DWZX-2020-646).

\section{Consent for publication}

All authors agreed to submit this manuscript.

\section{Competing interests}

The authors declare no conflicts of interests.

Received: 22 September 2021 Accepted: 2 November 2021

Published online: 20 November 2021

\section{References}

1. Parsons DW, Jones S, Zhang X, Lin JC, Leary RJ, Angenendt P, Mankoo P, Carter H, Siu IM, Gallia GL, Olivi A, McLendon R, Rasheed BA, Keir S, Nikolskaya T, Nikolsky Y, Busam DA, Tekleab H, Diaz LA Jr, Hartigan J, Smith DR, Strausberg RL, Marie SK, Shinjo SM, Yan H, Riggins GJ, Bigner DD, Karchin R, Papadopoulos N, Parmigiani G, Vogelstein B, Velculescu VE, Kinzler KW. An integrated genomic analysis of human glioblastoma multiforme. Science. 2008;321:1807-12.
2. Ahire E, Thakkar S, Darshanwad M, Misra M. Parenteral nanosuspensions: a brief review from solubility enhancement to more novel and specific applications. Acta Pharm Sin B. 2018;8:733-55.

3. Kadiyala P, Li D, Nuñez FM, Altshuler D, Doherty R, Kuai R, Yu M, Kamran N, Edwards M, Moon JJ, Lowenstein PR, Castro MG, Schwendeman A. High-density lipoprotein-mimicking nanodiscs for chemo-immunotherapy against glioblastoma multiforme. ACS Nano. 2019;13:1365-84.

4. Zhu Y, Liang J, Gao C, Wang A, Xia J, Hong C, Zhong Z, Zuo Z, Kim J, Ren H, Li S, Wang Q, Zhang F, Wang J. Multifunctional ginsenoside Rg3-based liposomes for glioma targeting therapy. J Control Release. 2021;330:641-57.

5. Stern II, Raizer JJ. Chemotherapy in the treatment of malignant gliomas. Expert Rev Anticancer Ther. 2006;6:755-67.

6. Ji X, Ge L, Liu C, Tang Z, Xiao Y, Chen W, Lei Z, Gao W, Blake S, De D, Shi B, Zeng X, Kong N, Zhang X, Tao W. Capturing functional two-dimensional nanosheets from sandwich-structure vermiculite for cancer theranostics. Nat Commun. 2021:12:1124.

7. Gao D, Chen T, Chen S, Ren X, Han Y, Li Y, Wang Y, Guo X, Wang H, Chen X, Guo M, Zhang YS, Hong G, Zhang X, Tian Z, Yang Z. Targeting hypoxic tumors with hybrid nanobullets for oxygen-independent synergistic photothermal and thermodynamic therapy. Nanomicro Lett. 2021;13:99.

8. Bobo D, Robinson KJ, Islam J, Thurecht KJ, Corrie SR. Nanoparticle-Based Medicines: A Review of FDA-Approved Materials and Clinical Trials to Date. Pharm Res. 2016;33:2373-87.

9. Wu HH, Zhou Y, Tabata Y, Gao JQ. Mesenchymal stem cell-based drug delivery strategy: from cells to biomimetic. J Control Release. 2019;294:102-13.

10. Fang RH, Kroll AV, Gao W, Zhang L. Cell Membrane Coating Nanotechnology. Adv Mater. 2018;30:e1706759.

11. Fang RH, Jiang Y, Fang JC, Zhang L. Cell membrane-derived nanomaterials for biomedical applications. Biomaterials. 2017;128:69-83.

12. Yang Z, Gao D, Guo X, Jin L, Zheng J, Wang Y, Chen S, Zheng X, Zeng L, Guo $M$, Zhang $X$, Tian Z. Fighting Immune Cold and Reprogramming Immunosuppressive Tumor Microenvironment with Red Blood Cell MembraneCamouflaged Nanobullets. ACS Nano. 2020;9:568.

13. Liu L, Bai X, Martikainen MV, Karlund A, Roponen M, Xu W, Hu G, Tasciotti E, Lehto VP. Cell membrane coating integrity affects the internalization mechanism of biomimetic nanoparticles. Nat Commun. 2021;12:5726.

14. Gao C, Huang Q, Liu C, Kwong CHT, Yue L, Wan JB, Lee SMY, Wang R. Treatment of atherosclerosis by macrophage-biomimetic nanoparticles via targeted pharmacotherapy and sequestration of proinflammatory cytokines. Nat Commun. 2020:11:2622.

15. Patravale VB, Date AA, Kulkarni RM. Nanosuspensions: a promising drug delivery strategy. J Pharm Pharmacol. 2004;56:827-40.

16. Xiao P, Wang J, Fang L, Zhao Z, Sun X, Liu X, Cao H, Zhang P, Wang D, Li Y. Nanovaccine-mediated cell selective delivery of neoantigens potentiating adoptive dendritic cell transfer for personalized immunization. Adv Funct Mater. 2021;21:04068.

17. Schwartzentruber DJ, Lawson DH, Richards JM, Conry RM, Miller DM, Treisman J, Gailani F, Riley L, Conlon K, Pockaj B, Kendra KL, White RL, Gonzalez R, Kuzel TM, Curti B, Leming PD, Whitman ED, Balkissoon J, Reintgen DS, Kaufman H, Marincola FM, Merino MJ, Rosenberg SA, Choyke P, Vena D, Hwu P. gp100 peptide vaccine and interleukin-2 in patients with advanced melanoma. N Engl J Med. 2011;364:2119-27.

18. Kong N, Zhang H, Feng C, Liu C, Xiao Y, Zhang X, Mei L, Kim JS, Tao W, Ji $X$. Arsenene-mediated multiple independently targeted reactive oxygen species burst for cancer therapy. Nat Commun. 2021;12:4777.

19. Mayer A, Zhang Y, Perelson AS, Wingreen NS. Regulation of T cell expansion by antigen presentation dynamics. Proc Natl Acad Sci U S A. 2019;116:5914-9.

20. Shemesh CS, Hsu JC, Hosseini I, Shen BQ, Rotte A, Twomey P, Girish S, Wu B. Personalized Cancer Vaccines: Clinical Landscape, Challenges, and Opportunities. Mol Ther. 2021;29:555-70.

21. Harari A, Graciotti M, Bassani-Sternberg M, Kandalaft LE. Antitumour dendritic cell vaccination in a priming and boosting approach. Nat Rev Drug Discov. 2020;19:635-52.

22. Wculek SK, Cueto FJ, Mujal AM, Melero I, Krummel MF, Sancho D. Dendritic cells in cancer immunology and immunotherapy. Nat Rev Immunol. 2020;20:7-24

23. Speiser DE, Ho PC, Verdeil G. Regulatory circuits of T cell function in cancer. Nat Rev Immunol. 2016;16:599-611.

24. Miyaike J, Iwasaki Y, Takahashi A, Shimomura H, Taniguchi H, Koide N, Matsuura K, Ogura T, Tobe K, Tsuji T. Regulation of circulating immune 
complexes by complement receptor type 1 on erythrocytes in chronic viral liver diseases. Gut. 2002;51:591-6.

25. Pan J, Wang $Y$, Zhang $C$, Wang $X$, Wang $H$, Wang J, Yuan $Y$, Wang $X$, Zhang $X$, Yu C, Sun SK, Yan XP. Antigen-Directed Fabrication of a Multifunctional Nanovaccine with Ultrahigh Antigen Loading Efficiency for Tumor Photothermal-Immunotherapy. Adv Mater. 2018;30:89.

26. Carreno BM, Magrini V, Becker-Hapak M, Kaabinejadian S, Hundal J, Petti AA, Ly A, Lie WR, Hildebrand WH, Mardis ER, Linette GP. Cancer immunotherapy A dendritic cell vaccine increases the breadth and diversity of melanoma neoantigen-specific T cells. Science. 2015;348:803-8.

27. Hu Z, Ott PA, Wu CJ. Towards personalized, tumour-specific, therapeutic vaccines for cancer. Nat Rev Immunol. 2018;18:168-82.

28. Munn DH, Mellor AL. IDO in the Tumor Microenvironment: Inflammation, Counter-Regulation, and Tolerance. Trends Immunol. 2016;37:193-207.

29. Gold P, Freedman SO. Demonstration of Tumor-Specific Antigens in Human Colonic Carcinomata by Immunological Tolerance and Absorption Techniques. J Exp Med. 1965;121:439-62.

30. Kroll AV, Fang RH, Jiang Y, Zhou J, Wei X, Yu CL, Gao J, Luk BT, Dehaini D, Gao W, Zhang L. Nanoparticulate Delivery of Cancer Cell Membrane Elicits Multiantigenic Antitumor Immunity. Adv Mater. 2017;29:18.

31. Liu W-L, Zou M-Z, Liu T, Zeng I-Y, Li X, Yu W-Y, Li C-X, Ye J-J, Song W, Feng J, Zhang X-Z. Cytomembrane nanovaccines show therapeutic effects by mimicking tumor cells and antigen resenting cells. Nat Commun. 2019;10:3199.

32. Chai Z, Ran D, Lu L, Zhan C, Ruan H, Hu X, Xie C, Jiang K, Li J, Zhou J, Wang J, Zhang Y, Fang RH, Zhang L, Lu W. Ligand-Modified Cell Membrane Enables the Targeted Delivery of Drug Nanocrystals to Glioma. ACS Nano. 2019;13:5591-601.

33. Chen Z, Zhao P, Luo Z, Zheng M, Tian H, Gong P, Gao G, Pan H, Liu L, Ma A, Cui H, Ma Y, Cai L. Cancer Cell Membrane-Biomimetic Nanoparticles for Homologous-Targeting Dual-Modal Imaging and Photothermal Therapy. ACS Nano. 2016;10:10049-57.

34. Rao L, Bu LL, Cai B, Xu JH, Li A, Zhang WF, Sun ZJ, Guo SS, Liu W, Wang TH, Zhao XZ. Cancer Cell Membrane-Coated Upconversion Nanoprobes for Highly Specific Tumor Imaging. Adv Mater. 2016;28:3460-6.

35. Xu X, Deng G, Sun Z, Luo Y, Liu J, Yu X, Zhao Y, Gong P, Liu G, Zhang P, Pan F, Cai L, Tang BZ. A Biomimetic Aggregation-Induced Emission Photosensitizer with Antigen-Presenting and Hitchhiking Function for Lipid Droplet Targeted Photodynamic Immunotherapy. Adv Mater. 2021;33:e2102322.

36. Baker J, Ajani J, Scotte F, Winther D, Martin M, Aapro MS, von Minckwitz G. Docetaxel-related side effects and their management. Eur J Oncol Nurs. 2009:13:49-59.

37. Xuan M, Shao J, Dai L, Li J, He Q. Macrophage Cell Membrane Camouflaged Au Nanoshells for in Vivo Prolonged Circulation Life and Enhanced Cancer Photothermal Therapy. ACS Appl Mater Interfaces. 2016;8:9610-8.

38. Dehaini D, Wei X, Fang RH, Masson S, Angsantikul P, Luk BT, Zhang Y, Ying M, Jiang Y, Kroll AV, Gao W, Zhang L. Erythrocyte-Platelet Hybrid Membrane Coating for Enhanced Nanoparticle Functionalization. Adv Mater. 2017;29:e234.

39. Liu W, Ruan M, Wang Y, Song R, Ji X, Xu J, Dai J, Xue W. Light-Triggered Biomimetic Nanoerythrocyte for Tumor-Targeted Lung Metastatic Combination Therapy of Malignant Melanoma. Small. 2018;14:e1801754.

40. Pooja D, Kulhari H, Adams DJ, Sistla R. Formulation and dosage of therapeutic nanosuspension for active targeting of docetaxel (WO 2014210485A1). Expert Opin Ther Pat. 2016;26:745-9.

41. Fang RH, Hu CM, Luk BT, Gao W, Copp JA, Tai Y, O'Connor DE, Zhang L. Cancer cell membrane-coated nanoparticles for anticancer vaccination and drug delivery. Nano Lett. 2014;14:2181-8.

42. Wang J, Tang W, Yang M, Yin Y, Li H, Hu F, Tang L, Ma X, Zhang Y, Wang Y. Inflammatory tumor microenvironment responsive neutrophil exosomesbased drug delivery system for targeted glioma therapy. Biomaterials. 2021:273:120784.

43. Zhang L, Zhang X, Lu G, Li F, Bao W, Song C, Wei W, Ma G. Cell Membrane Camouflaged Hydrophobic Drug Nanoflake Sandwiched with Photosensitizer for Orchestration of Chemo-Photothermal Combination Therapy. Small. 2019;15:e1902648.

44. Barberio AE, Smith SG, Correa S, Nguyen C, Nhan B, Melo M, Tokatlian T, Suh H, Irvine DJ, Hammond PT. Cancer Cell Coating Nanoparticles for Optimal Tumor-Specific Cytokine Delivery. ACS Nano. 2020;14:11238-53.

45. Fu S, Liang M, Wang Y, Cui L, Gao C, Chu X, Liu Q, Feng Y, Gong W, Yang M, Li Z, Yang C, Xie X, Yang Y, Gao C. Dual-Modified Novel Biomimetic
Nanocarriers Improve Targeting and Therapeutic Efficacy in Glioma. ACS Appl Mater Interfaces. 2019;11:1841-54.

46. Fan Y, Cui Y, Hao W, Chen M, Liu Q, Wang Y, Yang M, Li Z, Gong W, Song S, Yang Y, Gao C. Carrier-free highly drug-loaded biomimetic nanosuspensions encapsulated by cancer cell membrane based on homology and active targeting for the treatment of glioma. Bioact Mater. 2021;6:4402-14.

47. Wang D, Dong H, Li M, Cao Y, Yang F, Zhang K, Dai W, Wang C, Zhang X. Erythrocyte-Cancer Hybrid Membrane Camouflaged Hollow Copper Sulfide Nanoparticles for Prolonged Circulation Life and HomotypicTargeting Photothermal/Chemotherapy of Melanoma. ACS Nano. 2018;12:5241-52.

48. Han Y, Gao C, Wang H, Sun J, Liang M, Feng Y, Liu Q, Fu S, Cui L, Gao C, Li Y, Yang Y, Sun B. Macrophage membrane-coated nanocarriers Co-Modified by RVG 29 and TPP improve brain neuronal mitochondria-targeting and therapeutic efficacy in Alzheimer's disease mice. Bioact Mater. 2021;6:529-42.

49. Zhao ZX, Gao SY, Wang JC, Chen CJ, Zhao EY, Hou WJ, Feng Q, Gao LY, Liu $X Y$, Zhang $L R$, Zhang Q. Self-assembly nanomicelles based on cationic mPEG-PLA-b-Polyarginine(R15) triblock copolymer for siRNA delivery. Biomaterials. 2012;33:6793-807.

50. Liu R, Xiao W, Hu C, Xie R, Gao H. Theranostic size-reducible and no donor conjugated gold nanocluster fabricated hyaluronic acid nanoparticle with optimal size for combinational treatment of breast cancer and lung metastasis. J Control Release. 2018;278:127-39.

51. Sun H, Su J, Meng Q, Yin Q, Chen L, Gu W, Zhang P, Zhang Z, Yu H, Wang S, Li Y. Cancer-Cell-Biomimetic Nanoparticles for Targeted Therapy of Homotypic Tumors. Adv Mater. 2016;28:9581-8.

52. Yu Z, Zhou P, Pan W, Li N, Tang B. A biomimetic nanoreactor for synergistic chemiexcited photodynamic therapy and starvation therapy against tumor metastasis. Nat Commun. 2018;9:5044.

53. Xu X, Deng G, Sun Z, Luo Y, Liu J, Yu X, Zhao Y, Gong P, Liu G, Zhang P, Pan F, Cai L, Tang BZ. A Biomimetic Aggregation-Induced Emission Photosensitizer with Antigen-Presenting and Hitchhiking Function for Lipid Droplet Targeted Photodynamic Immunotherapy. Adv Mater. 2021;9:e2102322.

54. Mo R, Sun Q, Xue J, Li N, Li W, Zhang C, Ping Q. Multistage pH-responsive liposomes for mitochondrial-targeted anticancer drug delivery. Adv Mater. 2012;24:3659-65.

55. Khodarev NN, Yu J, Labay E, Darga T, Brown CK, Mauceri HJ, Yassari R, Gupta $\mathrm{N}$, Weichselbaum RR. Tumour-endothelium interactions in co-culture: coordinated changes of gene expression profiles and phenotypic properties of endothelial cells. J Cell Sci. 2003;116:1013-22.

56. Guan X, Lin L, Chen J, Hu Y, Sun P, Tian H, Maruyama A, Chen X. Efficient PD-L1 gene silence promoted by hyaluronidase for cancer immunotherapy. J Control Release. 2019;293:104-12.

57. Lai C, Duan S, Ye F, Hou X, Li X, Zhao J, Yu X, Hu Z, Tang Z, Mo F, Yang X, Lu $X$. The enhanced antitumor-specific immune response with mannoseand CpG-ODN-coated liposomes delivering TRP2 peptide. Theranostics. 2018;8:1723-39.

58. Zhai Y, Ran W, Su J, Lang T, Meng J, Wang G, Zhang P, Li Y. Traceable Bioinspired Nanoparticle for the Treatment of Metastatic Breast Cancer via NIR-Trigged Intracellular Delivery of Methylene Blue and Cisplatin. Adv Mater. 2018:45:e1802378.

59. Caruana I, Savoldo B, Hoyos V, Weber G, Liu H, Kim ES, Ittmann MM, Marchetti D, Dotti G. Heparanase promotes tumor infiltration and antitumor activity of CAR-redirected T lymphocytes. Nat Med. 2015;21:524-9.

60. Robert-Tissot C, Speiser DE. Anticancer teamwork: cross-presenting dendritic cells collaborate with therapeutic monoclonal antibodies. Cancer Discov. 2016;6:17-9.

61. Kim WY, Won M, Koo S, Zhang X, Kim JS. Mitochondrial H2Sn-Mediated Anti-Inflammatory Theranostics. Nanomicro Lett. 2021;13:168.

62. Landskron G, De la Fuente M, Thuwajit P, Thuwajit C, Hermoso MA. Chronic inflammation and cytokines in the tumor microenvironment. I Immunol Res. 2014;2014:149185.

63. Hao T, Chen Q, Qi Y, Sun P, Chen D, Jiang W, Liu K, Sun H, Li L, Ding J, Li Z. Biomineralized Gd2 O3 @HSA Nanoparticles as a Versatile Platform for Dual-Modal Imaging and Chemo-Phototherapy-Synergized Tumor Ablation. Adv Healthc Mater. 2019;8:e1901005.

64. Lokhov PG, Balashova EE. Antigenic Essence: Upgrade of Cellular Cancer Vaccines. Cancers (Basel). 2021;13:48. 
65. Liang X, Ye X, Wang C, Xing C, Miao Q, Xie Z, Chen X, Zhang X, Zhang H, Mei L. Photothermal cancer immunotherapy by erythrocyte membrane-coated black phosphorus formulation. J Control Release. 2019;296:150-61.

66. Wan YY, Flavell RA. Regulatory T cells, transforming growth factor-beta, and immune suppression. Proc Am Thorac Soc. 2007:4:271-6.

67. Shin J, Wood LD, Hruban RH, Hong SM. Desmin and CD31 immunolabeling for detecting venous invasion of the pancreatobiliary tract cancers. PLoS ONE. 2020;15:e0242571.

68. Fossella F, Pereira JR, von Pawel J, Pluzanska A, Gorbounova V, Kaukel E, Mattson KV, Ramlau R, Szczesna A, Fidias P, Millward M, Belani CP.
Randomized, multinational, phase III study of docetaxel plus platinum combinations versus vinorelbine plus cisplatin for advanced non-small-cell lung cancer: the TAX 326 study group. J Clin Oncol. 2003;21:3016-24.

\section{Publisher's Note}

Springer Nature remains neutral with regard to jurisdictional claims in published maps and institutional affiliations.
Ready to submit your research? Choose BMC and benefit from:

- fast, convenient online submission

- thorough peer review by experienced researchers in your field

- rapid publication on acceptance

- support for research data, including large and complex data types

- gold Open Access which fosters wider collaboration and increased citations

- maximum visibility for your research: over $100 \mathrm{M}$ website views per year

At BMC, research is always in progress.

Learn more biomedcentral.com/submissions 